\title{
On cause hypotheses of earthquakes with external tectonic plate and/or internal dense gas loadings
}

\author{
Zhong-qi Quentin Yue \\ Department of Civil Engineering, The University of Hong Kong, Pokfulam Road, Hong \\ Kong, China; Email : yueqzq@hku.hk
}

Presented at the 2013 SES Prager Medal Symposium in honor of Professor George Weng

\begin{abstract}
This paper examines and compares the two loading systems and their associated energy and basic stress fields in elastic crustal rock mass for the cause of tectonic earthquakes. The first loading system is an external loading system and associated with the conventional earthquake cause hypothesis of active fault elastic rebounding. The second is a combined loading system where the first external loading system is added with a dense gas loading in the interior of deep crustal rock faults/defects. It is associated with the methane gas hypothesis for the cause of tectonic earthquakes. Five elastic stresses in rock solids with some idealized faults and caverns are presented to illustrate the similarities and differences of the stress fields and the possible rupture failure modes in association of the two loading systems. The theoretical results can show that any changes in the local stress concentrations due the external loading alone can be reflected and noticed in the corresponding stresses at the far field. On the other hand, any changes in the local stress concentrations due to the internal gas loading cannot be observed and distinguished in the tectonic stress field at the far distance. These theoretical results can be used to well explain the consensus of earthquake unpredictability with present technology. The theoretical results can further show that the external tectonic loading alone can only cause shear ruptures in crustal fault rocks with high compressive stresses and such shear rupture or frictional failure is also difficult to occur because its shear plane has extremely high compressive normal stress. The combined loading can cause not only the shear ruptures but also tensile ruptures in crustal fault rocks and such shear and tensile ruptures are much easier to occur since its rupture plane can have very low compressive or even high tensile normal stress. It is argued that the earthquake energy is the volumetric expansion energy of dense gas mass escaped from the deep traps along crustal rock faults. The migration and expansion of the escaped dense gas mass in the crustal rock faults and defects cause the seismic body waves, the ground sounding, the seismic surface waves, the ground co-seismic ruptures and damages. Its rapid migration and expansion in thick water cause tsunamis in lakes and oceans. Its rapid migration and expansion in the atmosphere cause the sky to become cloudy. The dense methane gas is produced every day in the mantle and core of the Earth, migrates outward and accumulates and stores beneath the lower crustal rock in high compression. It forms a thin spherical layer of dense methane gas separating the cold crustal rocks and the hot mantle materials. Its leaking along deep faults or plate
\end{abstract}


boundaries causes earthquakes and supplies to shallow gas and oil reservoirs beneath secondary traps in adjacent basins of the upper crustal rock mass.

Keywords: Tectonic earthquakes; earthquake energy and cause; earthquake mechanism; loading systems; methane gas; fracture mechanics; prediction; thin gas spherical layer

\section{Introduction}

Earthquakes occur every day. Damaging earthquakes occur every month and/or every year. Statistical data of earthquake events over many years have shown that each year, there are about 20 major earthquakes with magnitudes from M7.0 to M7.9 that can have serious damage results, 100 strong earthquakes with magnitude from M6.1 to M6.9 that can be potentially destructive and 31,000 earthquakes with magnitudes from M2.5 to M6.0 that can have minor to moderate damage to structures. In addition, there is one great earthquake with magnitude $\mathrm{M} \geq 8.0$ that can make total destruction in every five years. In particular and for example, a total of 23 major earthquakes with magnitudes $\geq$ M7.0, 86 strong earthquakes with magnitudes from M6.0 to M6.9, and 324 earthquakes with magnitudes from M5.0 to M5.9 happened in Mainland China within the 43 years from 1966 to 2008.

A mega-earthquake suddenly releases a large to extremely large amount of kinetic energy within a few tens to two hundreds seconds and over ten to hundreds kilometer distances in the Earth's crust and on ground surface. It also generates seismic waves that can be received globally and co-seismic ground damages such as co-seismic ruptures and landslides. For example, the 2008 Wenchuan Earthquake M8.0 released the radiated seismic strain energy of $6.3 \times 10^{16}$ to $8.8 \times 10^{17}$ Joule within 110 seconds, and caused 69,195 fatalities, 374,176 injured, 18,392 people listed as missing, as well as huge ground damages and building collapses over the Longmenshan (Dragon's Gate Mountain) fault zone of $300 \mathrm{~km}$ long and 50 km wide.

However, such vast, dramatic, rapid and devastating kinetic actions over large regions of the Earth's crustal rocks and the ground soils cannot be known or predicted by people at few years, few weeks, few days, few hours, and/or few minutes before they are happening. Seismologists have developed and used seismometers to report the locations and magnitudes of earthquakes within minutes of their occurrences. But, they cannot predict next damaging earthquakes at present [1-5]. Therefore, damage earthquakes have caused and would continue to cause huge disasters, fatalities and injuries to our human beings, which is an urgent and challenging problem. This problem itself alone has demonstrated that it is necessary to reexamine the cause of tectonic earthquakes in addition to the conventional cause of active fault elastic rebounding hypothesis [6-7], since the sudden release of huge kinetic energy during a tremor must follow the laws of thermodynamics such as energy conservation and the three Newton's laws of motion. 
Furthermore, based on the results of earthquakes, it is evident that an earthquake is a mechanical process involving elastic deformation, plastic damage and brittle ruptures of crustal rocks and soils under external and/or internal loadings. Once again, we have to ask the following two most basic and important questions. What is the loading that can cause earthquakes (or tectonic earthquakes)? What is the earthquake energy that can suddenly release in the crustal rock mass causing ground damages and seismic waves over long distance?

To address the two questions, this paper examines and compares the two loading systems and their associated energy and basic stress fields in elastic crustal rock mass. One loading system is an external loading system that is associated with the conventional earthquake cause of active fault elastic rebounding hypothesis [6-7]. The other loading system is an internal loading system that is associated with the gas hypothesis for the cause of tectonic earthquakes [8-14].

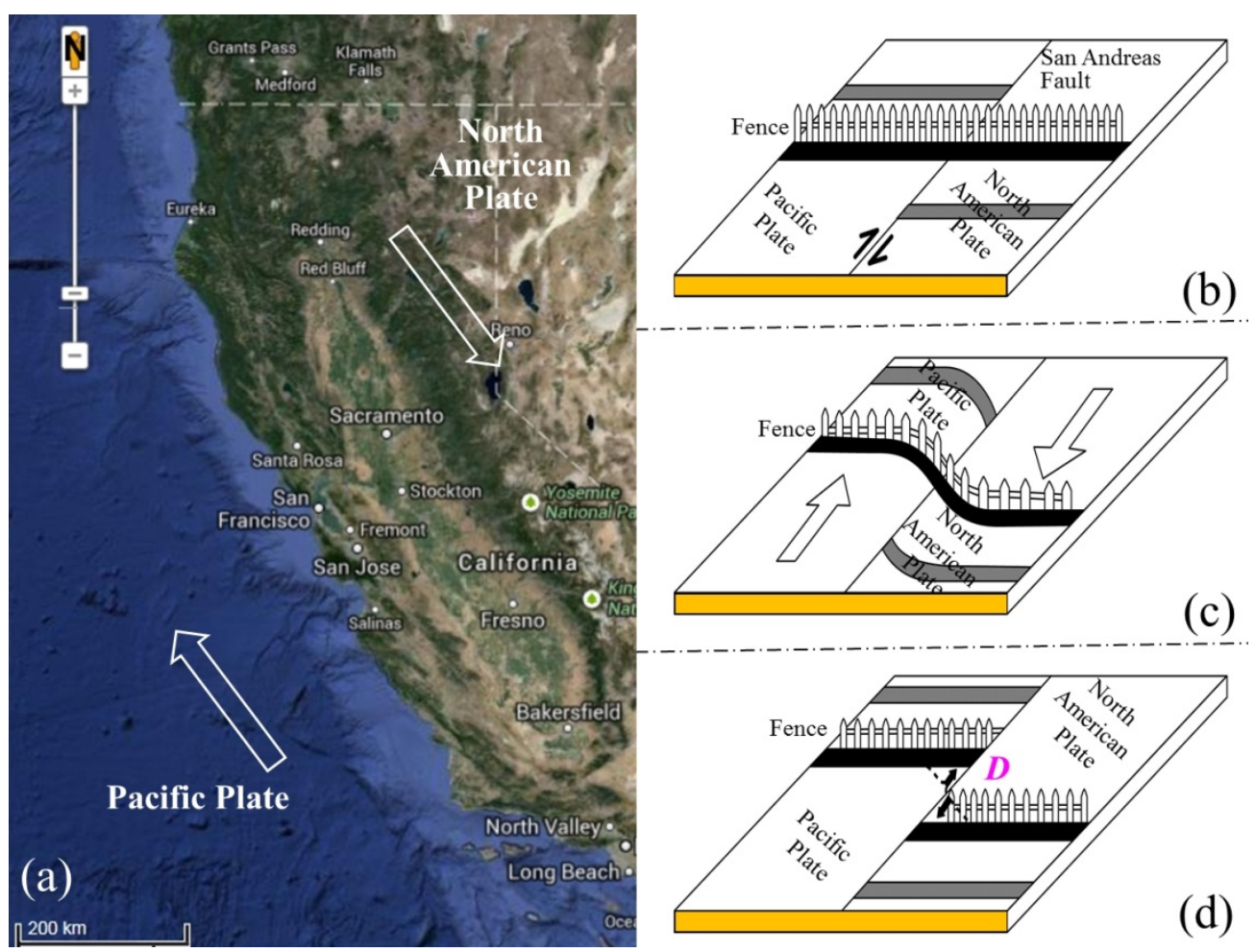

Fig. 1 The elastic rebound hypothesis of brittle ruptures along active geological fault in crustal rocks for cause of the 1906 San Francisco Earthquake M7.8 on April 18, 1906 (the Reid hypothesis)

\section{Two loading systems for cause of tectonic earthquakes}

\subsection{The external loading system for the Reid hypothesis}

The conventional elastic rebound hypothesis for cause of earthquakes states that tectonic earthquakes are caused by sudden rupture of brittle and elastic rocks at interlocked zones 
along active deep geological faults in the Earth's crust when the applied stresses exceed their tensile and/or shear strengths. This hypothesis was developed by Professor H.F. Reid about 100 years ago after the investigation of the 1906 San Francisco Earthquake M7.8 on April 18, 1906 [6-7]. As shown in Fig.1, the San Andreas Fault passing through San Francisco region was experienced right-lateral strike-slip fault movement. The movement was caused by the slow displacement of the Pacific Plate toward the northwest with respect to the North American Plate. The ground rocks on both sides of the San Andreas Fault would gradually distort to deform the "S" shape as shown in Fig.1b. At the point of sudden rupture of the interlocked fault zone, the distortion would be released and the two parts along the fault would rebound back to have a permanent dislocation offer D, as shown in Fig.1c. Since then, many researchers have adopted the Reid hypothesis to investigate the details of the causes and mechanisms of actual earthquakes and to predict next damaging earthquakes. They have developed and used various theories and methods in continuum mechanics, solid mechanics, fracture mechanics and elastodynamics in their examinations of the global and regional stress fields and seismic waves in crustal rocks associated with earthquakes [15-39].

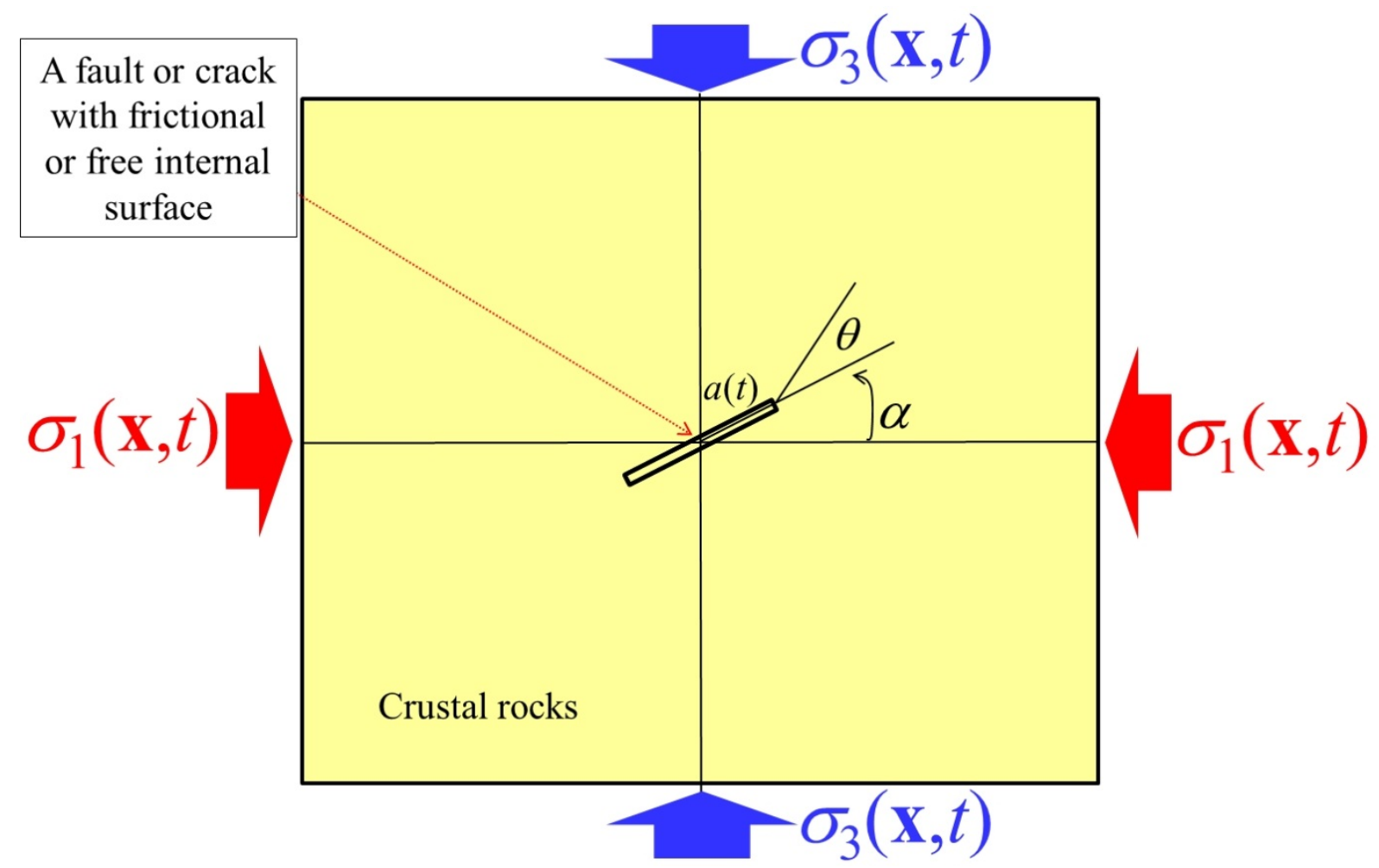

Fig.2 The basic fracture mechanics model for the Reid hypothesis of the cause of tectonic earthquake due to external loading

Based on these studies, the most basic mechanic model for the Reid hypothesis on the cause of tectonic earthquakes can be shown in Fig.2. The elastic crustal rock has a fault or crack with frictional or free internal surface. It is subjected to external loading of both vertical gravity force and the lateral relative movements of tectonic plates. The loading stresses at the far field can be expressed as the maximum principal stress $\sigma_{1}(\mathbf{x}, t)$, the intermediate principal 
stress $\sigma_{2}(\mathbf{x}, t)$ (not shown in Fig.2), and the minimum principal stress $\sigma_{3}(\mathbf{x}, t)$, where $\sigma_{1}(\mathbf{x}, t)>$ $\sigma_{2}(\mathbf{x}, t)>\sigma_{3}(\mathbf{x}, t)$ and the compression is positive). The shear stress state in Fig. 1 is only the shear component of the general stress state in Fig.2 (also see Fig.5(a)). These external loading stresses can change with both the time $t$ and the locations $\mathbf{x}$ in the three dimensional space of the Earth. Under these external loadings, the crustal rock solids with fault or defects would experience deformation and distortion. Once the induced rock stresses are increased to be or greater than the rock tensile or shear strengths, the rock solids would occur some brittle ruptures or slips and their faults or defects would propagate, which would generate earthquakes associated with seismic waves and ground damages.

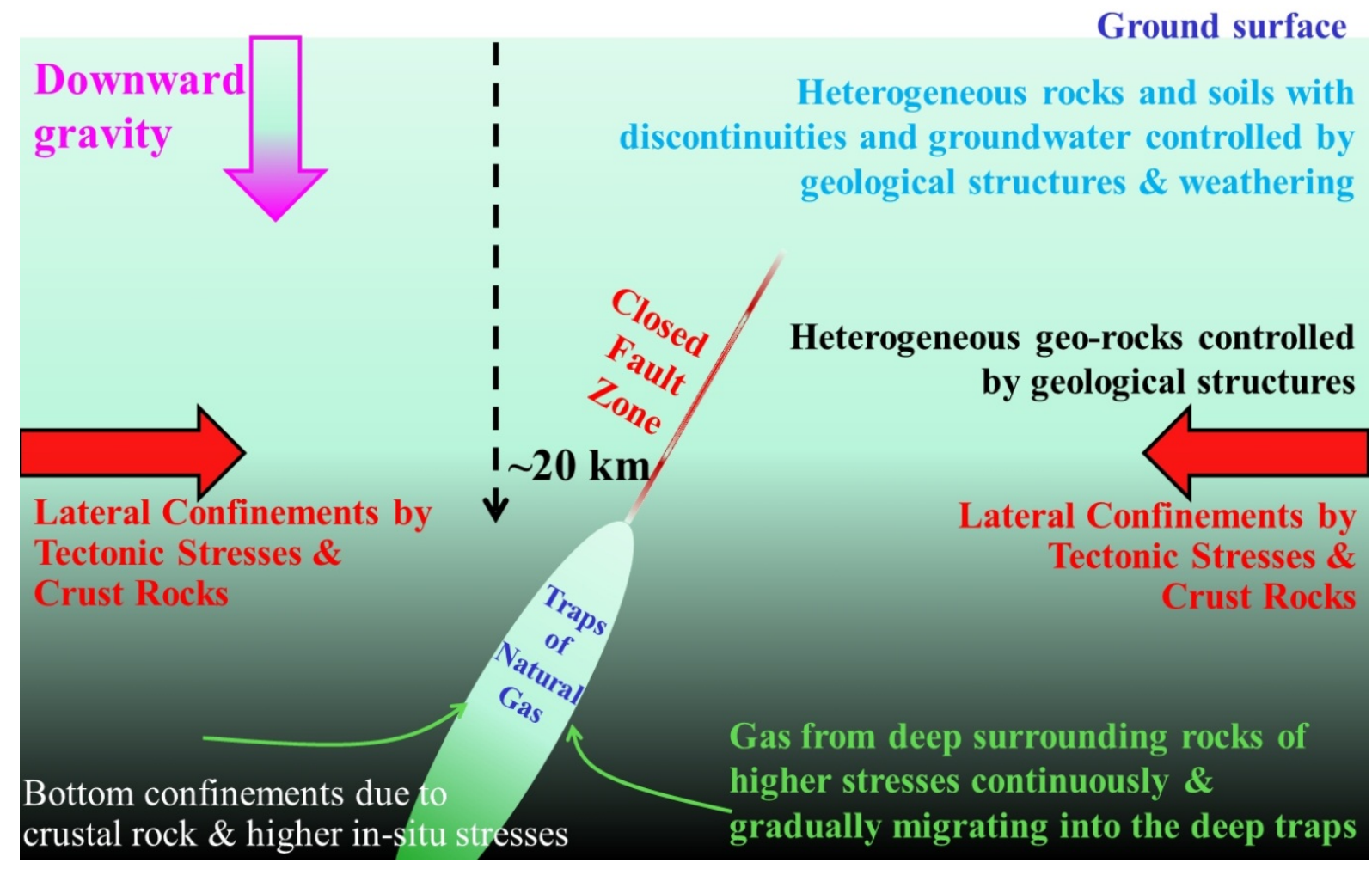

Fig.3 Active gas energy - passive rock faulting model for cause of tectonic earthquakes (the gas hypothesis)

\subsection{The internal loading system for the gas hypothesis}

The gas hypothesis for the cause of tectonic earthquakes has been proposed by the author in August 2008, after his active and persistent investigation of the Wenchuan Earthquake of May 12, 2008 [8-14]. Based on many earthquake-relevant natural phenomena that happened before, during and after the Wenchuan Earthquake, he had to propose a gas hypothesis to logically and consistently explain and interpret these phenomena. Some of these phenomena are listed as follows: 1) huge ground sounding were heard by local people earlier and then great ground motion felt by them a few second later; 2) the sky at epicenters suddenly became dust \& dark during and immediately after the main shock; 3) the air temperatures at the epicenter areas were decreased quickly and substantially after ground shocking at 14:28 
local time; 4) several hours after the main shock, the whole epicenter areas had heavy rainfalls from the evening of May 12 to the evening of May 14, 2008; 5) Many heavy and/or huge ground damage, ruptures and maintain rock avalanches were isolated and concentrated along the deep geological faults; 6) The co-seismic ground ruptures were found in soils and coal beds and were variable, irregular, short, and isolated along the geological faults, 7) no co-seismic ground ruptures were found in hard rocks. 8) there were substantial increases in the amount of natural gas volumes and their pressures in many gas fields in Sichuan basin and/or in front of Longmenshan before and more rapidly after the main shock; 9) land subsidence of vast areas on both sides of the Longmenshan fault had permanent horizontal displacements toward to the fault and permanent vertical settlements downward.

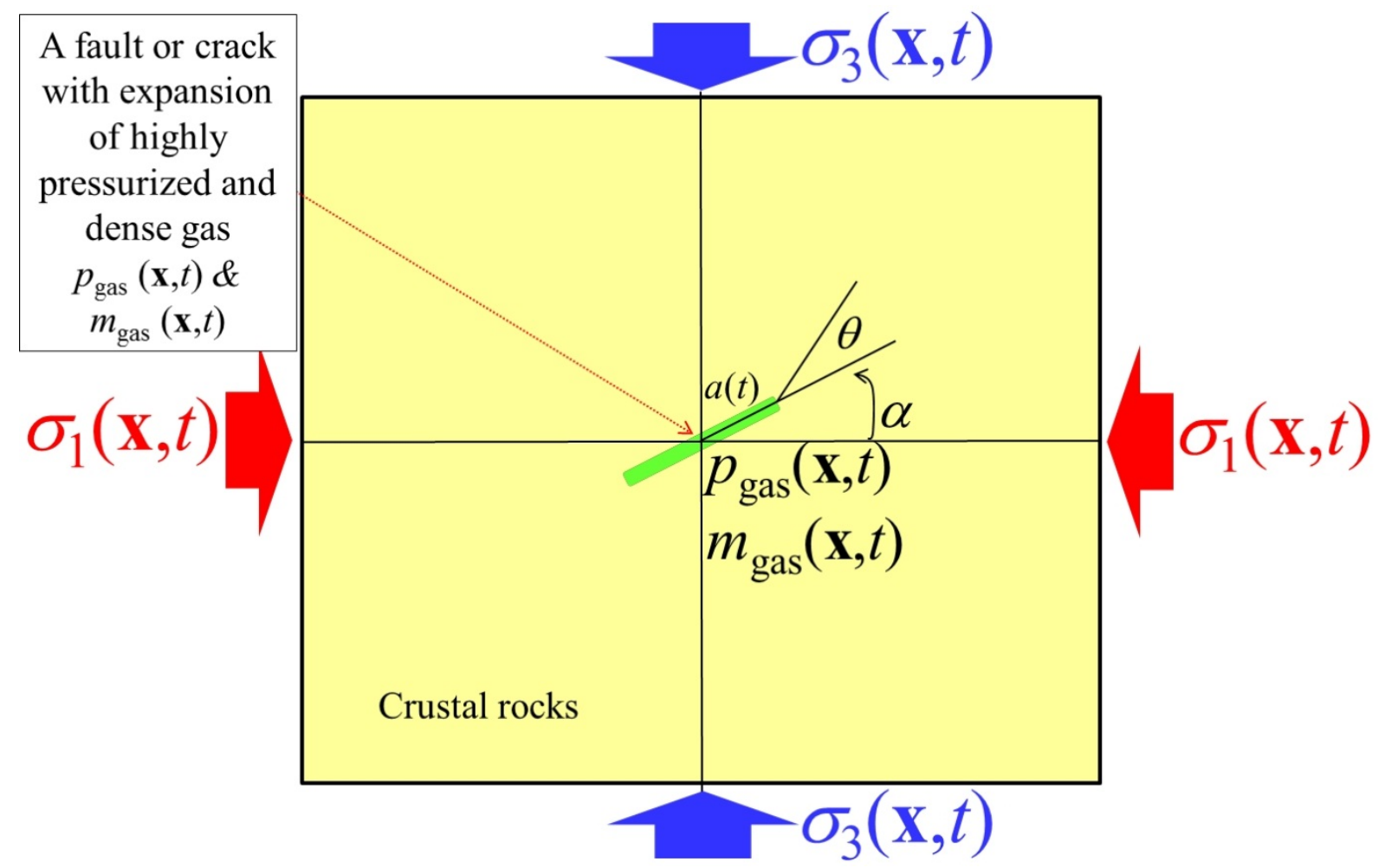

Fig.4 The basic fracture mechanics model for the gas hypothesis of the cause of tectonic earthquakes due to both external \& internal loading

Accordingly, the sudden, rapid, dramatic and damaging earthquake process is an adiabatic process of the interaction between rapid upward expansion and migration of extremely highly compressed and dense natural (methane) gas and its surrounding crustal rocks and ground soils. The gas expansion and migration are confined and constrained by the inward gravity, the tectonic stresses and the rigidness and strengths of the crustal rocks. Because of the extremely high pressure drops in front of the moving gas mass, the gas migration speed in the fault zones can be several $\mathrm{km} / \mathrm{s}$. The interaction is instantaneous and flashing. It can be complete within few to tens and to hundreds seconds. The natural gas is produced in core and/or mantle and gradually accumulated in the traps below crustal fault rocks. It escapes from its traps in deep fault zones of the lower crustal rocks once its pressure induced stresses 
in the surrounding compressed trap rocks reaches their tensile or shear strength. The physical expansion power of the extremely highly compressed gas mass generates seismic waves and ground damages and displacements during its rapid migration process in the crustal rocks and soils.

Based on the studies, the most basic mechanic model for the gas hypothesis on the cause of tectonic earthquakes can be shown in Figs.3 and 4. Both the external tectonic and gravity loadings and the crustal rock and fault conditions in Figs. 3 and 4 are exactly same as those given in Figs. 1 and 2 for the Reid hypothesis. The only difference is the presence of the internal loading from the compressed gas mass in the fault or crack or defect for the gas hypothesis in Figs. 3 and 4 . The gas mass has the pressure $p_{\text {gas }}(\mathbf{x}, t)$ and a total mass $m_{\text {gas }}(\mathbf{x}, t)$ that are variable with time and locations. This compressed gas mass is absent in the Reid hypothesis.

In this gas model, the external loadings $\sigma_{1}(\mathbf{x}, t), \sigma_{2}(\mathbf{x}, t)$ and $\sigma_{3}(\mathbf{x}, t)$ provide the confining and constraint and compressive stresses to the tensile stresses generated in the crustal rocks and faults by the internal gas pressure $p_{\text {gas }}(\mathbf{x}, t)$ and mass $m_{\text {gas }}(\mathbf{x}, t)$. Under the both external and internal loadings, the crustal rock solids with fault or defects would experience deformation and distortion. Once the combined rock stresses are increased to be or greater than the rock tensile or shear strengths, the rock solids would occur some brittle ruptures or slips, their faults or defects would propagate, and part of the compressed gas mass would migrate and expand into the opening spaces, which would generate earthquakes associated with seismic waves and ground damages.

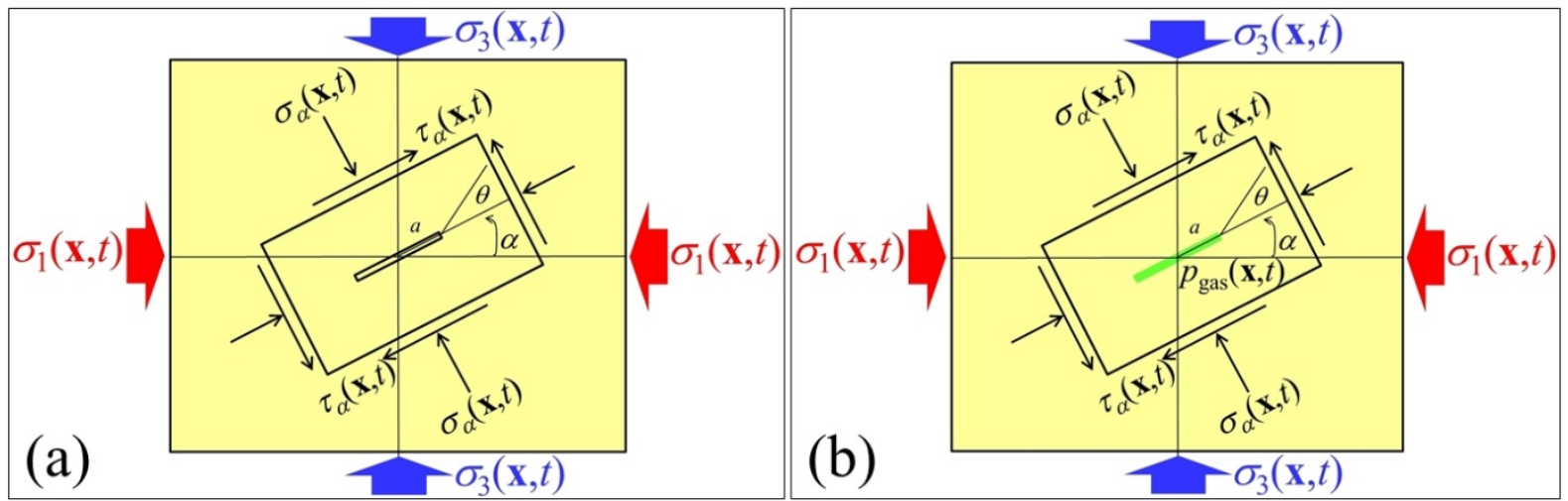

Fig.5 Comparison of the two loading systems around a fault or defect in a rock mass: (a) for the Reid hypothesis; (b) for the gas hypothesis

\section{Basic stress fields of two loading systems for comparisons}

There are many solutions available in open literatures for the stress fields in elastic solids due to the two loading systems. Five examples, as shown in Figs. 5 to 14 are given below to compare the stress fields and failure (or crack) mechanism of the crustal rocks due to the two loading systems. 


\subsection{Rock with inclined fault under biaxial compression and/or internal pressure}

The external loading $\sigma_{1}(\mathbf{x}, t)$ and $\sigma_{3}(\mathbf{x}, t)$ at the far distance to the inclined fault in Figs.2 and 4 can be re-arranged as those shown in Fig.5 according to the fault surface inclination angle $\alpha$ to the $\sigma_{1}(\mathbf{x}, t)$ direction. Accordingly, the external normal stress $\sigma_{\alpha}(\mathbf{x}, t)$ and shear stress $\tau_{d}(\mathbf{x}, t)$ loading on the plane at far distance and parallel to the inclined fault surface in the solid rock can be expressed as follows.

$$
\begin{aligned}
& \sigma_{\alpha}(\mathbf{x}, t)=\frac{\sigma_{1}(\mathbf{x}, t)+\sigma_{3}(\mathbf{x}, t)}{2}-\frac{\sigma_{1}(\mathbf{x}, t)-\sigma_{3}(\mathbf{x}, t)}{2} \cos 2 \alpha . \\
& \tau_{\alpha}(\mathbf{x}, t)=\frac{\sigma_{1}(\mathbf{x}, t)-\sigma_{3}(\mathbf{x}, t)}{2} \sin 2 \alpha .
\end{aligned}
$$

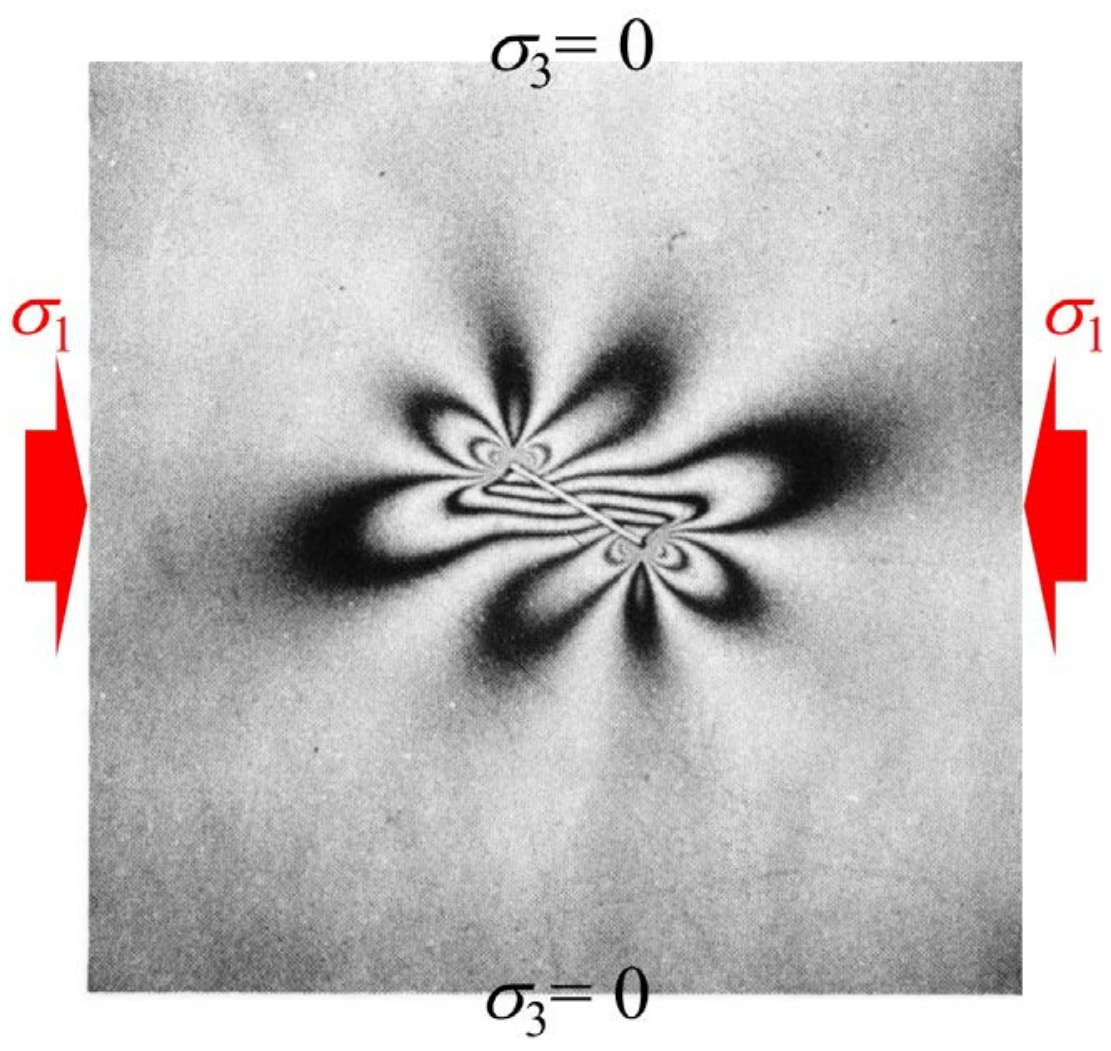

Fig.6 Typical photoelastic isochromatic pattern in a glass plate containing an elliptical crack for the plate subjected to the uniaxial compression (after [40])

If both the external loading $\sigma_{1}(\mathbf{x}, t)$ and $\sigma_{3}(\mathbf{x}, t)$ are compressive, the external normal stress loading $\sigma_{\alpha}(\mathbf{x}, t)$ would be compressive too. The fault would be compressed and would not have any crack propagations of the opening fracture mode I. The fault may experience shear failure if one of the three crack failure criteria is reached.

1) Mohr-Coulomb shear failure criteriion

$$
\tau_{\alpha}(\mathbf{x}, t) \geq c(\mathbf{x}, t)+\sigma_{\alpha}(\mathbf{x}, t) \tan [\phi(\mathbf{x}, t)] .
$$

2) Griffith shear crack criterion 


$$
\tau_{\text {effective }}(\mathbf{x}, t)=\tau_{\alpha}(\mathbf{x}, t)-\sigma_{\alpha}(\mathbf{x}, t) \tan [\phi(\mathbf{x}, t)] \geq \frac{K_{I I}(\mathbf{x}, t)}{\sqrt{\pi a(\mathbf{x}, t)}} .
$$

3) Griffith-Mohr fracture initiation criterion

$$
\tau_{\alpha}^{2}(\mathbf{x}, t)=4 \sigma_{t}(\mathbf{x}, t)\left(\sigma_{t}(\mathbf{x}, t)-\sigma_{\alpha}(\mathbf{x}, t)\right) .
$$

where $c(\mathbf{x}, t), \phi(\mathbf{x}, t), K_{I I}(\mathbf{x}, t)$ and $\sigma_{t}(\mathbf{x}, t)$ are the internal cohesion, internal frictional angle, fracture toughness, and uniaxial tensile strength of the fault surface or its surrounding rocks, respectively. They are also variable with time and locations. The above equations (1) to (5) are applicable to the loading system associated with the Reid hypothesis. Fig. 6 shows a typical photoelastic isochromatic pattern given by Hoek and Bieniawski [40] for a glass plate with an inclined crack subjected to the uniaxial compression. More detailed analysis on the brittle rock fracture can be found in their paper.

For the loading system associated with the gas hypothesis, the equation (1) may be changed to

$$
\sigma_{\alpha}(\mathbf{x}, t)=\frac{\sigma_{1}(\mathbf{x}, t)+\sigma_{3}(\mathbf{x}, t)}{2}-\frac{\sigma_{1}(\mathbf{x}, t)-\sigma_{3}(\mathbf{x}, t)}{2} \cos 2 \alpha-p_{\text {gas }}(\mathbf{x}, t)
$$

If both $\sigma_{1}(\mathbf{x}, t)$ and $\sigma_{3}(\mathbf{x}, t)$ are still compressive, the $\sigma_{\alpha}(\mathbf{x}, t)$ would be either compressive or tensile. Furthermore, if $\sigma_{\alpha}(\mathbf{x}, t)$ is compressive, the fault would not have any crack propagations of the opening fracture mode I. The fault may experience shear failure if one of the three criteria in equations (3) to (5) is reached. The gas would also escape and migrate into the new crack opening.

Furthermore, if $\sigma_{\alpha}(\mathbf{x}, t)$ is tensile, the fault would have crack propagations in the forms of the opening fracture mode I and the shear failure mode. The following failure criteria may be applicable.

$$
\begin{aligned}
& \tau_{\alpha}(\mathbf{x}, t) \geq c(\mathbf{x}, t) \\
& \tau_{\text {effective }}(\mathbf{x}, t)=\tau_{\alpha}(\mathbf{x}, t) \geq \frac{K_{I I}(\mathbf{x}, t)}{\sqrt{\pi a(\mathbf{x}, t)}} . \\
& \left|\sigma_{\alpha}(\mathbf{x}, t)\right| \geq \sigma_{t}(\mathbf{x}, t) .
\end{aligned}
$$

or

$$
\left|\sigma_{\alpha}(\mathbf{x}, t)\right| \geq \frac{K_{I}(\mathbf{x}, t)}{\sqrt{\pi a(\mathbf{x}, t)}}
$$

\subsection{Rock with Griffith fault under external tension and internal pressure}

The simplest example of the loading system shown in Figs.2, 4 and 5 is illustrated in Fig.7, where a Griffith crack in an elastic rock subject to either an uniaxial tension $\sigma_{0}$ for the Reid hypothesis (Fig.7a) or an internal uniform pressure $p_{0}$ for the gas hypothesis (Fig.7b). For the 
uniform and uniaxial tension loading $\sigma_{0}$ at far distance and perpendicular to the fault, the stresses in the elastic rock under the plane strain condition are given by

$$
\begin{gathered}
\sigma_{x x}(x, y)=\sigma_{0}\left\{\frac{r}{\sqrt{r_{1} r_{2}}} \cos \left(\theta-\frac{\theta_{1}+\theta_{2}}{2}\right)-\frac{a^{2} r}{\sqrt{\left(r_{1} r_{2}\right)^{3}}} \sin \theta \sin \left[\frac{3}{2}\left(\theta_{1}+\theta_{2}\right)\right]-1\right\} \\
\sigma_{y y}(x, y)=\sigma_{0}\left\{\frac{r}{\sqrt{r_{1} r_{2}}} \cos \left(\theta-\frac{\theta_{1}+\theta_{2}}{2}\right)+\frac{a^{2} r}{\sqrt{\left(r_{1} r_{2}\right)^{3}}} \sin \theta \sin \left[\frac{3}{2}\left(\theta_{1}+\theta_{2}\right)\right]-1\right\}+\sigma_{0} \\
\sigma_{x y}(x, y)=\sigma_{0}\left\{\frac{a^{2} r}{\sqrt{\left(r_{1} r_{2}\right)^{3}}} \sin \theta \cos \left[\frac{3}{2}\left(\theta_{1}+\theta_{2}\right)\right]\right\}
\end{gathered}
$$

Particularly, the stresses along the Griffith fault $(y=0)$ can be simplified as follows.

$$
\begin{aligned}
& \sigma_{x x}(x, 0)=\left\{\begin{array}{cc}
-\sigma_{0} & |x|<a \\
\sigma_{0}\left(\frac{x}{\sqrt{x^{2}-a^{2}}}-1\right) & |x|>a
\end{array}\right\} . \\
& \sigma_{y y}(x, 0)=\left\{\begin{array}{cc}
0 & |x|<a \\
\sigma_{0} \frac{x}{\sqrt{x^{2}-a^{2}}} & |x|>a
\end{array}\right\} . \\
& \sigma_{x y}(x, 0)=0 \quad|x|<\infty .
\end{aligned}
$$
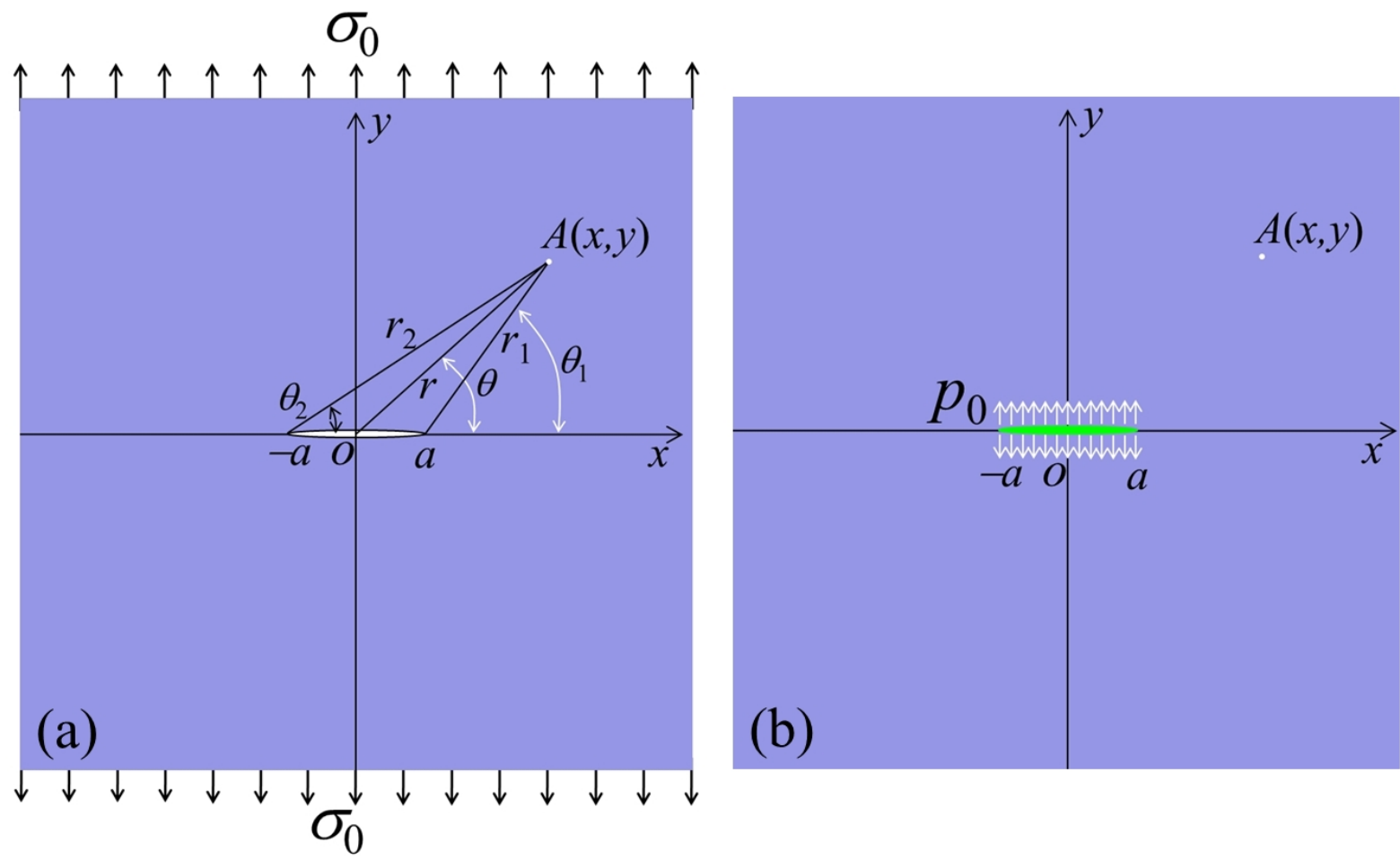

Fig.7 A Griffith crack in an elastic rock subject to either (a) an uniaxial tension $\sigma_{0}$ for the Reid hypothesis or (b) an internal uniform pressure $p_{0}$ for the gas hypothesis 
For the uniform pressure loading $p_{0}$ in the interior of the fault, the stresses in the elastic rock under the plane strain condition can be expressed in the following equations.

$$
\begin{gathered}
\sigma_{x x}(x, y)=p_{0}\left\{\frac{r}{\sqrt{r_{1} r_{2}}} \cos \left(\theta-\frac{\theta_{1}+\theta_{2}}{2}\right)-\frac{a^{2} r}{\sqrt{\left(r_{1} r_{2}\right)^{3}}} \sin \theta \sin \left[\frac{3}{2}\left(\theta_{1}+\theta_{2}\right)\right]-1\right\} \\
\sigma_{y y}(x, y)=p_{0}\left\{\frac{r}{\sqrt{r_{1} r_{2}}} \cos \left(\theta-\frac{\theta_{1}+\theta_{2}}{2}\right)+\frac{a^{2} r}{\sqrt{\left(r_{1} r_{2}\right)^{3}}} \sin \theta \sin \left[\frac{3}{2}\left(\theta_{1}+\theta_{2}\right)\right]-1\right\} \\
\sigma_{x y}(x, y)=p_{0}\left\{\frac{a^{2} r}{\sqrt{\left(r_{1} r_{2}\right)^{3}}} \sin \theta \cos \left[\frac{3}{2}\left(\theta_{1}+\theta_{2}\right)\right]\right\} \\
\sigma_{x x}(x, 0)=\sigma_{y y}(x, 0)=\left\{p_{0}\left(\frac{x}{\sqrt{x^{2}-a^{2}}}-1\right)|x|>a\right\} . \\
\sigma_{x y}(x, 0)=0 \quad|x|<\infty .
\end{gathered}
$$

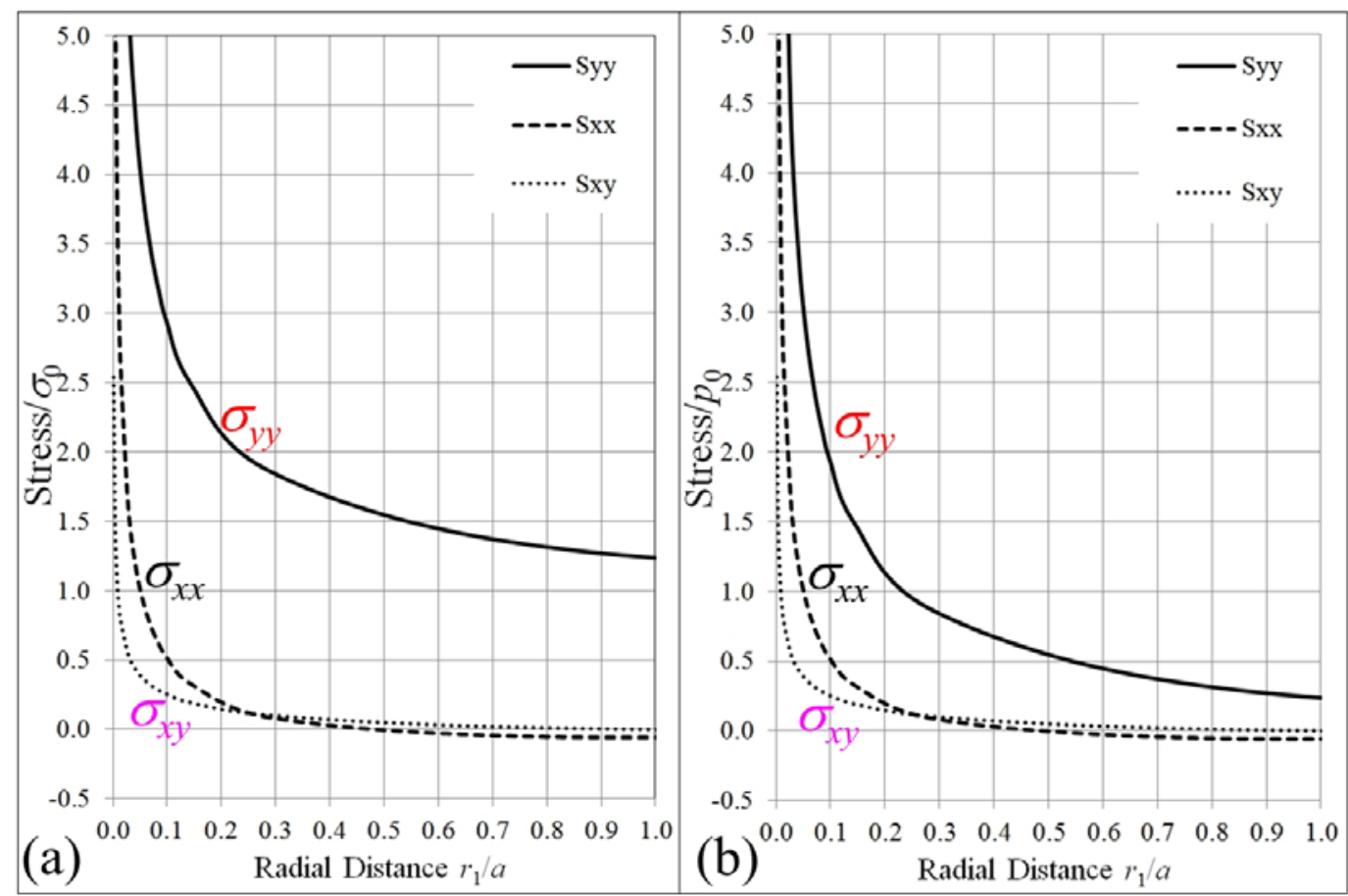

Fig.8 Stress concentrations at a Griffith crack in an elastic rock subject to either (a) an uniaxial tension $\sigma_{0}$ for the Reid hypothesis or (b) an internal uniform pressure $p_{0}$ for the gas hypothesis

The stress solution expressions for the stresses given in equations (11) to (16) are the same as those given in (17) to (21), except the normal stress $\sigma_{y y}(x, y)$ in (18) or (20) has a reduction of the uniform applied pressure to (12) or (15), respectively [41-42]. As the distance to the crack 
tip increases, the stresses in equations (11), (13), (14), (16) to (21) would decrease to zero following the inverse proportion to the distance square, while the normal stress in equations (12) and (15) would reduce to the applied uniaxial tensile stress. Fig. 8 shows the monotonic stress reductions with respect to the increase of the radial distance $r_{1} / a$, where $\theta_{1}=\pi / 4$. It can be observed that the presence of the crack only affects the local stress values near the crack tip. As the radial distance $r_{1} / a$ approach to 1.0, the stresses become the uniform uniaxial tensile stress field (Fig. 8a) or the zero stress field (Fig. 8b).

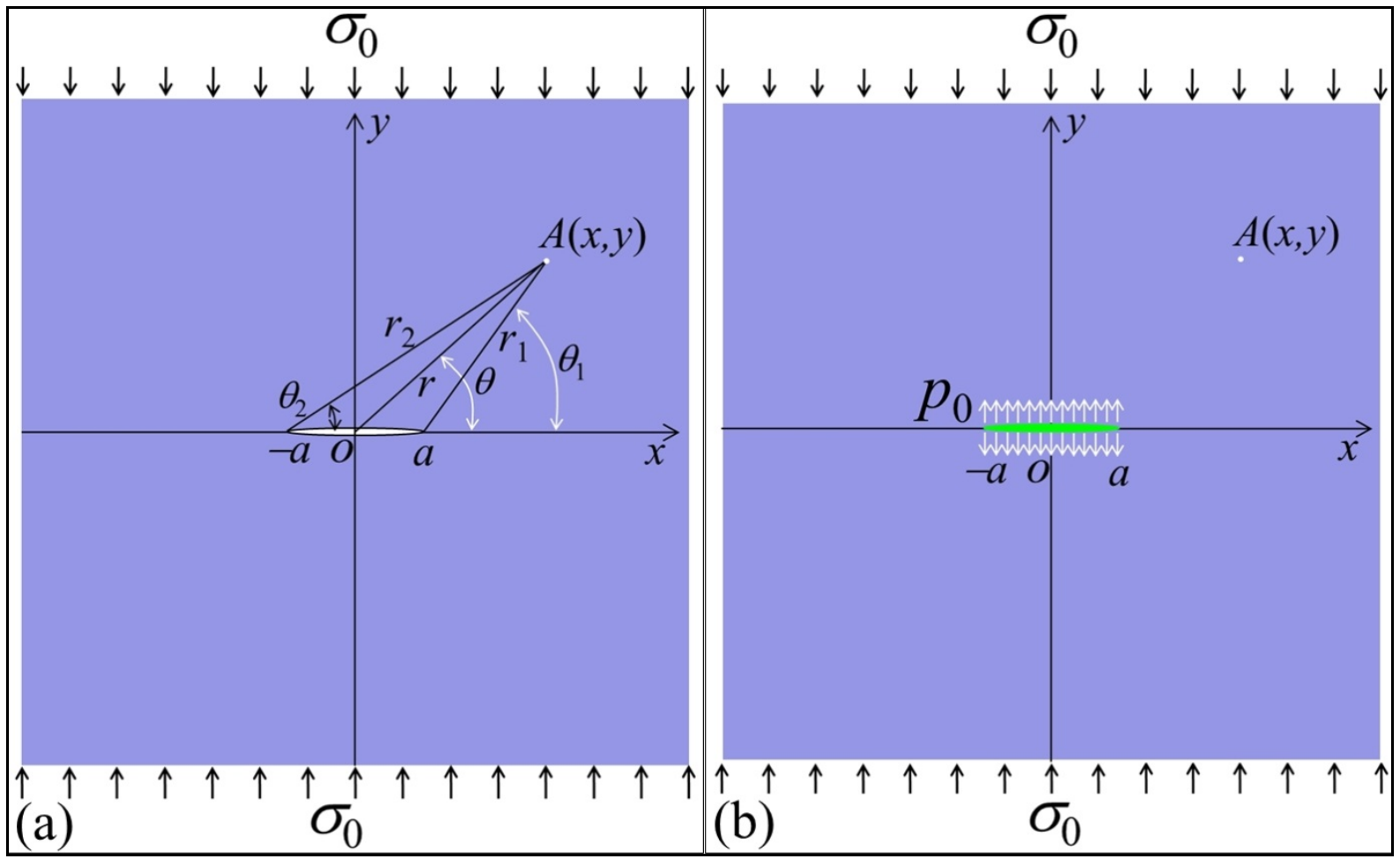

Fig.9 A Griffith crack in an elastic rock subject to either (a) an uniaxial compression $\sigma_{0}$ for the Reid hypothesis or (b) both uniaxial compression $\sigma_{0}$ and internal uniform pressure $p_{0}$ for the gas hypothesis

\subsection{Rock with Griffith fault under external compression and internal pressure}

The second simplest example of the loading system shown in Figs. 2, 4 and 5 is illustrated in Fig.9, where a Griffith crack in an elastic rock subject to either an uniaxial compression $\sigma_{0}$ for the Reid hypothesis (Fig.9a) or both uniaxial compression $\sigma_{0}$ and internal uniform pressure $p_{0}$ for the gas hypothesis (Fig.9b). For the uniform and uniaxial compression loading $\sigma_{0}$ at far distance and perpendicular to the fault, the stresses in the elastic rock under the plane strain condition are given by

$$
\begin{aligned}
& \sigma_{x x}(x, y)=0 \\
& \sigma_{y y}(x, y)=\sigma_{0}
\end{aligned}
$$




$$
\sigma_{x y}(x, y)=0
$$

For both the uniaxial compression $\sigma_{0}$ at the far boundaries and the uniform pressure loading $p_{0}$ in the interior of the fault, the stresses in the elastic rock under the plane strain condition can be expressed in the following equations with the linear superposition principle. Furthermore, under the uniaxial compression $\sigma_{0}$, the Griffth fault crack has to be closed and compacted if the uniaxial compression $\sigma_{0}$ is greater than the internal uniform gas pressure $p_{0}$. In other words, the internal gas pressure $p_{0}$ has to be equal to $\sigma_{0}$ at its lowest equilibrium condition. Accordingly, the following condition can be reached if the gas can increase its pressure via some geological and/or geophysical mechanism [14]:

$$
p_{0}-\sigma_{0} \geq 0
$$

Therefore, we have the following stress field.

$$
\begin{aligned}
& \sigma_{x x}(x, y)=-\left(p_{0}-\sigma_{0}\right)\left\{\frac{r}{\sqrt{r_{1} r_{2}}} \cos \left(\theta-\frac{\theta_{1}+\theta_{2}}{2}\right)-\frac{a^{2} r}{\sqrt{\left(r_{1} r_{2}\right)^{3}}} \sin \theta \sin \left[\frac{3}{2}\left(\theta_{1}+\theta_{2}\right)\right]-1\right\} \\
& \sigma_{y y}(x, y)=-\left(p_{0}-\sigma_{0}\right)\left\{\frac{r}{\sqrt{r_{1} r_{2}}} \cos \left(\theta-\frac{\theta_{1}+\theta_{2}}{2}\right)+\frac{a^{2} r}{\sqrt{\left(r_{1} r_{2}\right)^{3}}} \sin \theta \sin \left[\frac{3}{2}\left(\theta_{1}+\theta_{2}\right)\right]-1\right\}+\sigma_{0} \\
& \sigma_{x y}(x, y)=-\left(p_{0}-\sigma_{0}\right)\left\{\frac{a^{2} r}{\sqrt{\left(r_{1} r_{2}\right)^{3}}} \sin \theta \cos \left[\frac{3}{2}\left(\theta_{1}+\theta_{2}\right)\right]\right\} \\
& \sigma_{x x}(x, 0)=\left\{\begin{array}{cc}
-\left(p_{0}-\sigma_{0}\right) & |x|<a \\
-\left(p_{0}-\sigma_{0}\right)\left(\frac{x}{\sqrt{x^{2}-a^{2}}}-1\right) & |x|>a
\end{array}\right\} \cdot \\
& \sigma_{y y}(x, 0)=\left\{\begin{array}{cc}
\left(p_{0}-\sigma_{0}\right)+\sigma_{0} & |x|<a \\
-\left(p_{0}-\sigma_{0}\right)\left(\frac{x}{\sqrt{x^{2}-a^{2}}}-1\right)+\sigma_{0} & |x|>a
\end{array}\right\} . \\
& \sigma_{x y}(x, 0)=0 \quad \begin{array}{c}
|x|<\infty \\
|x|
\end{array}
\end{aligned}
$$

The stress field in equations (22) to (24) shows that the rock solid with the crack would not be able to experience the opening mode of rupture. However, the stress field in equations (25) to (31) shows the rock solid with the crack would be able to experience the opening mode of rupture as long as the internal gas pressure $p_{0}$ within the crack can increase or the surrounding compression $\sigma_{0}$ can reduce with time. The local stress concentrations at the crack tip are proportional to the difference between the internal gas pressure $p_{0}$ and the uniaxial compression $\sigma_{0}$ at the far field. They decrease quickly to the uniaxial compression stress state (22) to (24) as the radial distance to the crack tip increases to more than the half of the crack length. 


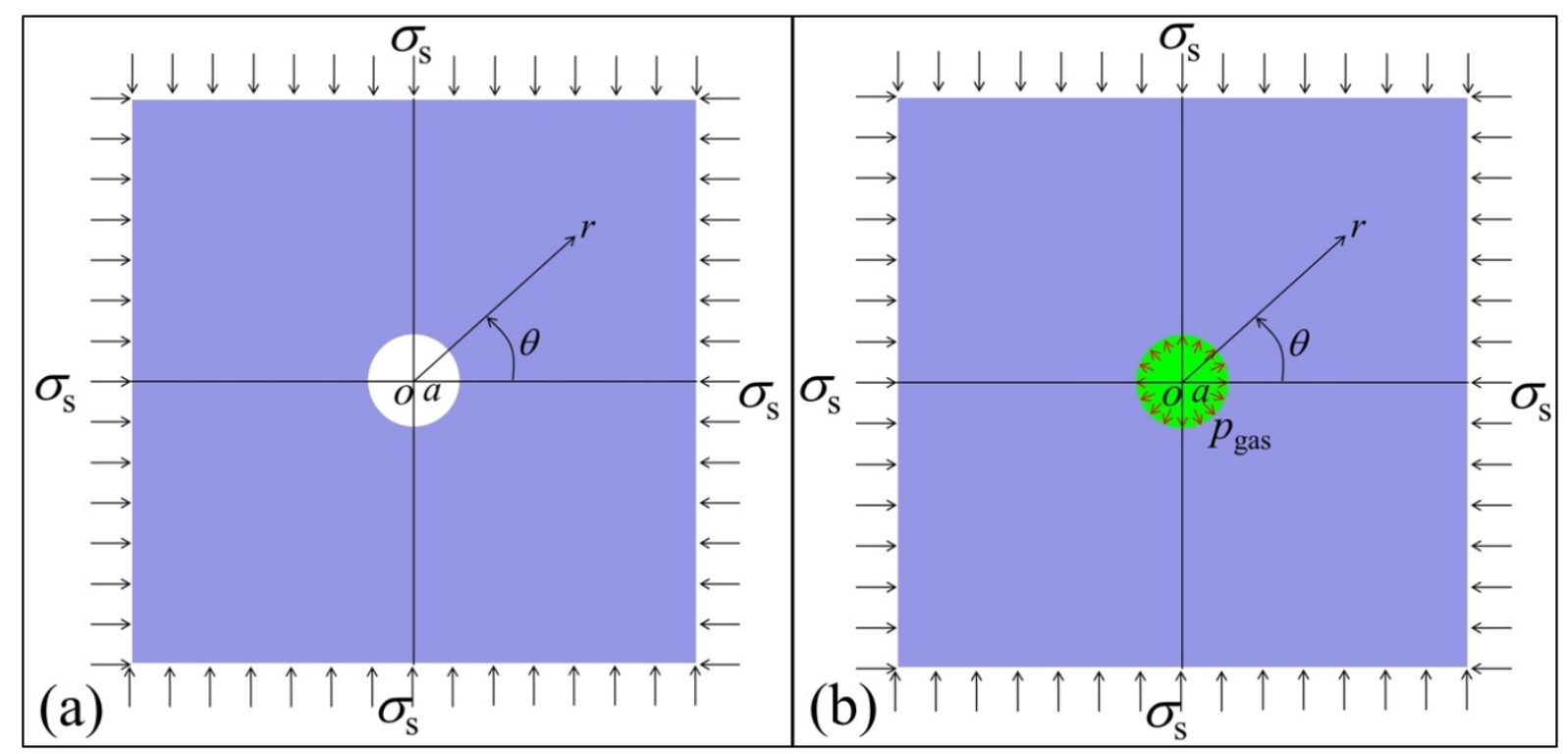

Fig.10 Comparison of the two loading systems in rock mass with a circular cylindrical or spherical hole: (a) for the Reid hypothesis; (b) for the gas hypothesis

\subsection{Rock solid with circular cylindrical hole subjected to the two loadings}

The third simplest example of the loading system shown in Figs. 2, 4 and 5 is illustrated in Fig.10, where a circular cylindrical hole in an elastic rock subject to either a uniform compression $\sigma_{\mathrm{s}}$ at far distance to the hole for the Reid hypothesis (Fig.10a) or both uniform compression $\sigma_{\mathrm{s}}$ and internal uniform pressure $p_{\text {gas }}$ for the gas hypothesis (Fig.10b). For the uniform compression loading $\sigma_{\mathrm{s}}$ at far distance and perpendicular to the circular cylindrical hole, the stresses in the elastic rock under the plane strain condition are given by (see [43])

$$
\begin{aligned}
& \sigma_{r r}(r)=\sigma_{s}\left(1-\frac{a^{2}}{r^{2}}\right) \\
& \sigma_{\theta \theta}(r)=\sigma_{s}\left(1+\frac{a^{2}}{r^{2}}\right) \\
& \sigma_{y y}(r)=2 v \sigma_{s} \\
& \sigma_{r \theta}=\sigma_{\theta y}=\sigma_{y r}=0 \\
& \tau_{\max }=\frac{1}{2}\left(\sigma_{\theta \theta}(r)-\sigma_{r r}(r)\right)=\frac{\sigma_{s} a^{2}}{r^{2}}
\end{aligned}
$$

For both the uniform compression loading $\sigma_{\mathrm{s}}$ at far distance and perpendicular to the circular cylindrical hole and the internal gas pressure $p_{\text {gas }}$, the stresses in the elastic rock under the plane strain condition are given by 


$$
\begin{aligned}
& \sigma_{r r}=\sigma_{s}\left(1-\frac{a^{2}}{r^{2}}\right)+p_{g a s} \frac{a^{2}}{r^{2}} \\
& \sigma_{\theta \theta}=\sigma_{s}\left(1+\frac{a^{2}}{r^{2}}\right)-p_{g a s} \frac{a^{2}}{r^{2}} \\
& \sigma_{y y}(r)=2 v \sigma_{s} \\
& \sigma_{r \theta}=\sigma_{\theta y}=\sigma_{y r}=0 \\
& \tau_{\max }=\frac{1}{2}\left(\sigma_{\theta \theta}(r)-\sigma_{r r}(r)\right)=\left(\sigma_{s}-p_{g a s}\right) \frac{a^{2}}{r^{2}}
\end{aligned}
$$
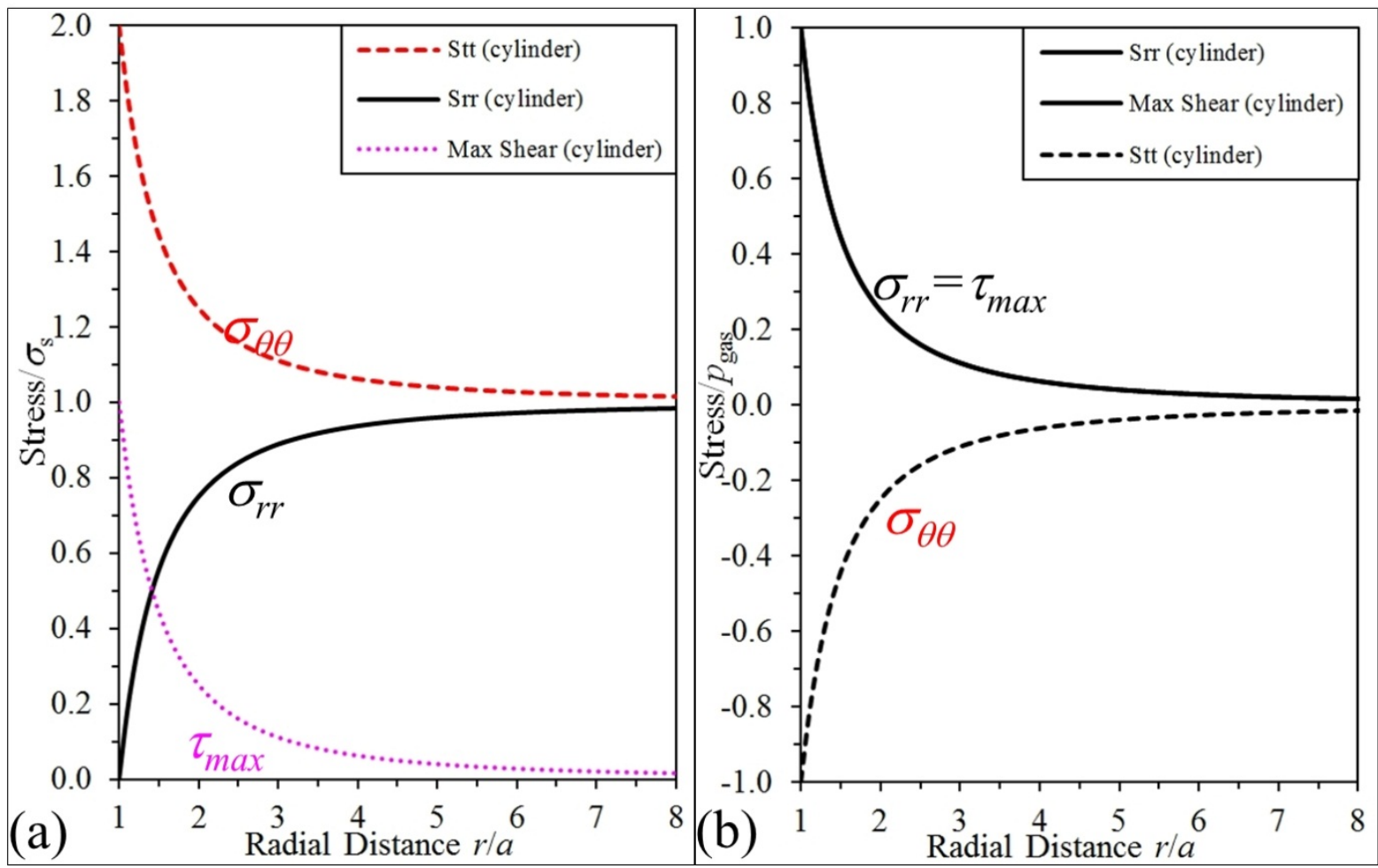

Fig.11 Stress concentrations around a circular cylindrical hole in an elastic rock subject to (a) the uniform external compression $\sigma_{\mathrm{s}}$ and (b) the uniform internal pressure $p_{\text {gas }}$

Comparing the equations (32) to (36) with those (37) to (41), it is evident that the equations (37) to (41) have linearly added the additional stresses from the loading of the internal gas pressure $p_{\text {gas. }}$ Fig. 11 shows the stress concentrations in the rock solid near the circular cylindrical hole. The two normal stresses $\sigma_{r r}$ and $\sigma_{\theta \theta}$ for the external compression loading quickly reduce to the applied stress $\sigma_{\mathrm{s}}$ and the associated shear stress quickly reduces to zero as the radial distance increases (Fig. 11a). All the stresses for the internal gas pressure loading quickly reduce to zero as the radial distance increases (Fig.11b). The effect of the hole to the stress field is limited to the region within 3 to 4 times of the cylindrical hole radius $a$. 
Fig. 12 shows the linear increases of the stress concentrations at the interior surface of a circular cylindrical hole in an elastic rock subjected to both the external uniform compression pressure $\sigma_{\mathrm{s}}$ and the internal gas pressure $p_{\text {gas }}$ with respect to the ratio $p_{\text {gas }} / \sigma_{\mathrm{s}}$. It is evident that the hoop normal stress $\sigma_{\theta \theta}$ would become tensile (negative value) after $p_{\text {gas }} / \sigma_{\mathrm{s}} \geq 2$. Therefore, the following tensile or shear failure criteria may be adopted for local crack at the cylindrical hole.

$$
\begin{aligned}
& p_{\text {gasmintensile }} \geq 2 \sigma_{s}+\sigma_{\text {tensilestrength }} \\
& p_{\text {gas minshear }} \geq \sigma_{s}+\sigma_{\text {shearstrength }}
\end{aligned}
$$

where $\sigma_{\text {tensilestrength }}$ and $\sigma_{\text {shearstrength }}$ are the rock tensile and shear strength respectively.

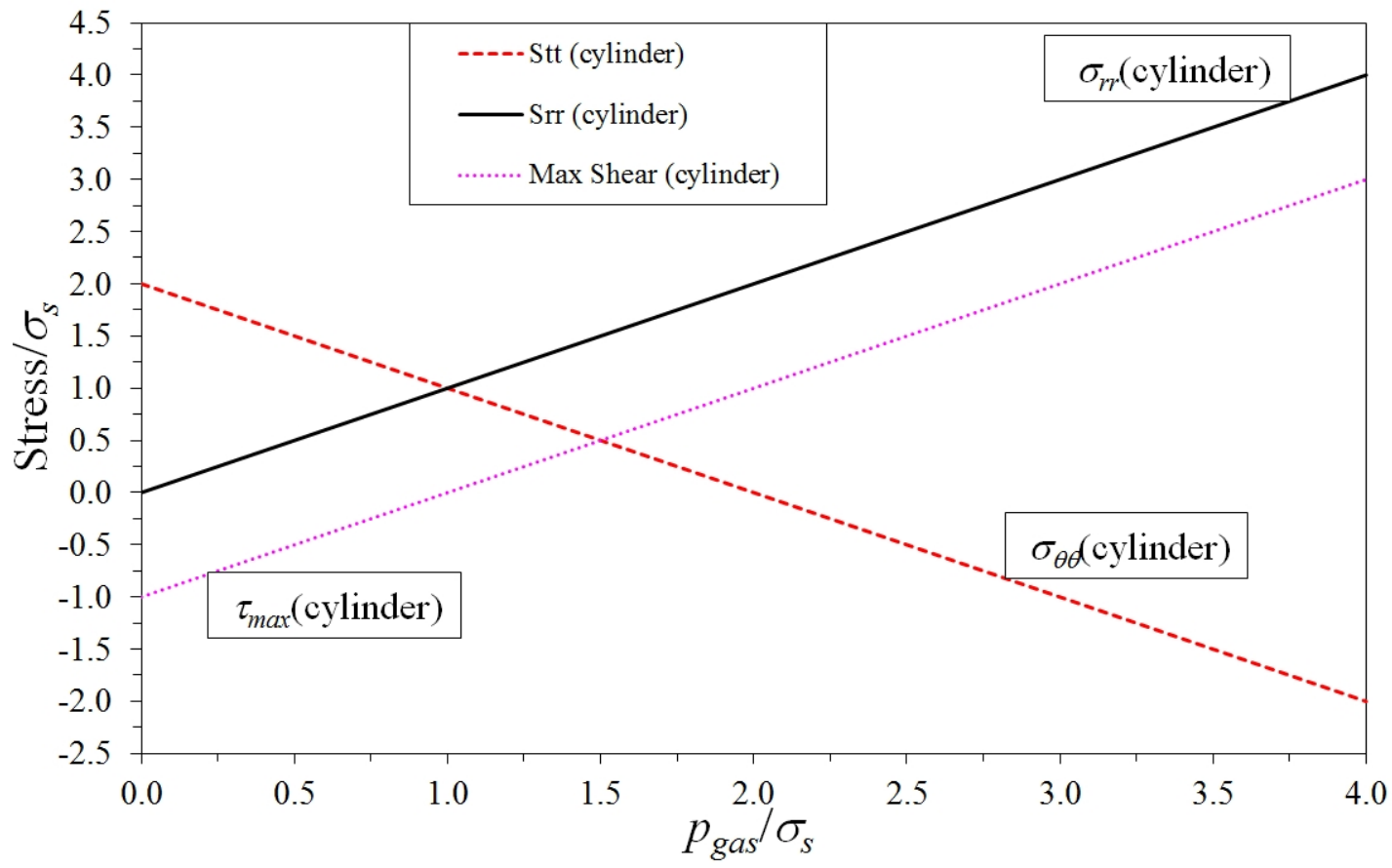

Fig.12 Stress concentrations at the interior surface of a circular cylindrical hole in an elastic rock subjected to both the external uniform compression pressure $\sigma_{\mathrm{s}}$ and the internal gas pressure $p_{\text {gas }}$ with respect to the ratio $p_{\text {gas }} / \sigma_{\mathrm{s}}$

\subsection{Rock solid with spherical hole subjected to the two loadings}

The four simplest example of the loading system shown in Figs. 2, 4 and 5 is also illustrated in Fig.10, where a spherical hole in an elastic rock subject to either a uniform compression $\sigma_{\mathrm{s}}$ at far distance to the hole for the Reid hypothesis (Fig.10a) or both uniform compression $\sigma_{\mathrm{s}}$ and internal uniform pressure $p_{\text {gas }}$ for the gas hypothesis (Fig.10b). For the uniform compression loading $\sigma_{\mathrm{s}}$ at far distance, the non-zero stresses in the elastic rock are given by

$$
\begin{aligned}
& \sigma_{r r}=\sigma_{s}\left(1-\frac{a^{3}}{r^{3}}\right) \\
& \sigma_{\theta \theta}=\sigma_{\varphi \varphi}=\sigma_{s}\left(1+\frac{a^{3}}{2 r^{3}}\right)
\end{aligned}
$$




$$
\tau_{\max }=\frac{1}{2}\left(\sigma_{\theta \theta}(r)-\sigma_{r r}(r)\right)=\frac{3 \sigma_{s} a^{3}}{4 r^{3}}
$$

For both the uniform compression loading $\sigma_{\mathrm{s}}$ and the internal gas pressure $p_{\text {gas }}$, the non-zero stresses in the elastic rock are given by

$$
\begin{aligned}
& \sigma_{r r}=\sigma_{s}\left(1-\frac{a^{3}}{r^{3}}\right)+p_{g a s} \frac{a^{3}}{r^{3}} \\
& \sigma_{\theta \theta}=\sigma_{\varphi \varphi}=\sigma_{s}\left(1+\frac{a^{3}}{2 r^{3}}\right)-p_{g a s} \frac{a^{3}}{2 r^{3}} \\
& \tau_{\max }=\frac{1}{2}\left(\sigma_{\theta \theta}(r)-\sigma_{r r}(r)\right)=\left(\sigma_{s}-p_{g a s}\right) \frac{3 a^{3}}{4 r^{3}}
\end{aligned}
$$

Comparing the equations (44) to (46) with those (47) to (49), it is evident that the equations (47) to (49) have linearly added the additional stresses from the loading of the internal gas pressure $p_{\text {gas }}$. Fig. 13 shows the stress concentrations in the rock solid near the spherical hole. The two normal stresses $\sigma_{r r}$ and $\sigma_{\theta \theta}$ for the external compression loading quickly reduce to the applied stress $\sigma_{\mathrm{s}}$ and the associated shear stress quickly reduces to zero as the radial distance increases (Fig. 13a). All the stresses for the internal gas pressure loading quickly reduce to zero as the radial distance increases (Fig.13b). The effect of the hole to the stress field is limited to the region within 2 to 3 times of the spherical hole radius $a$.

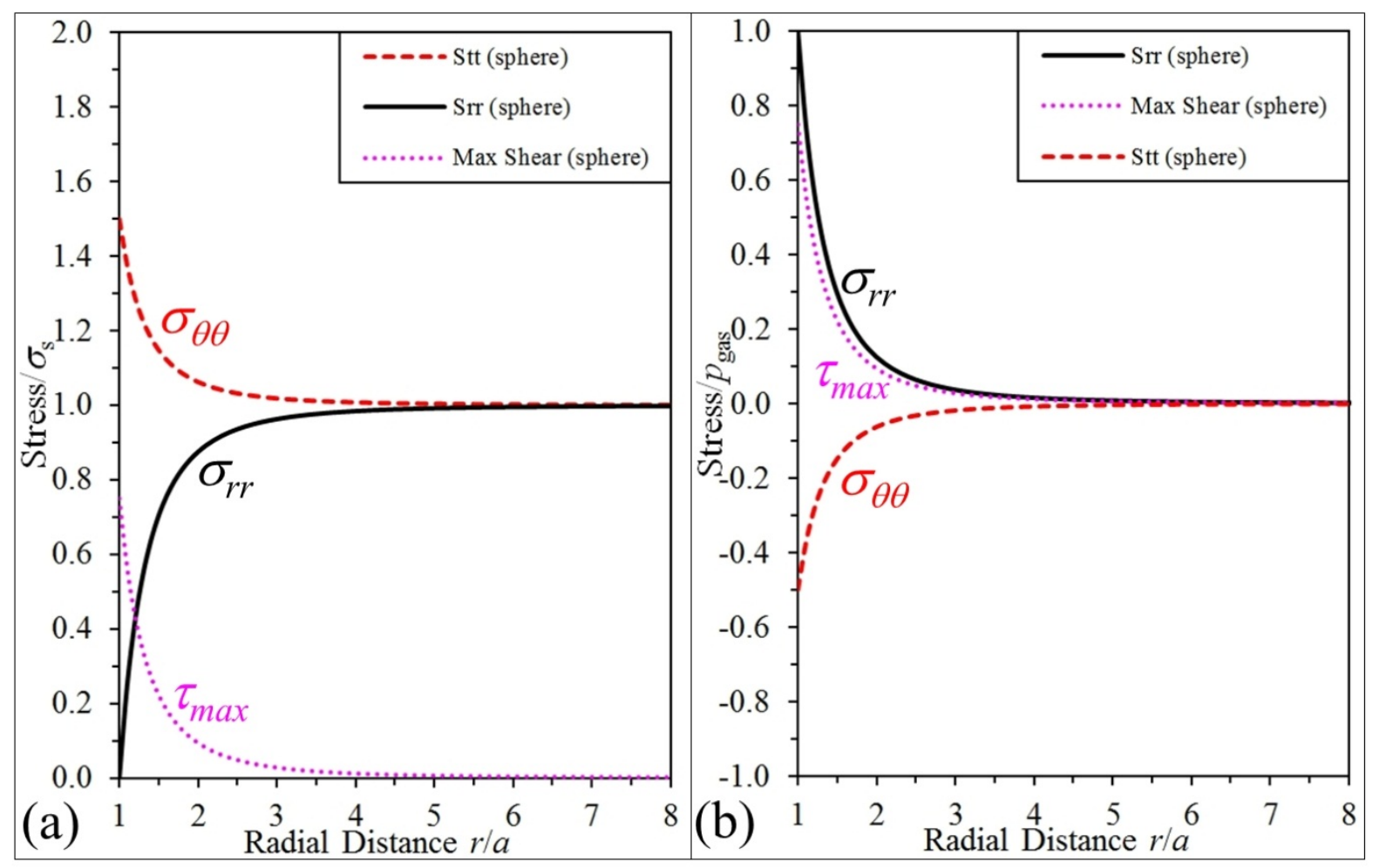

Fig.13 Stress concentrations around a spherical hole in an elastic rock subject to (a) the uniform external compression $\sigma_{\mathrm{s}}$ and (b) the uniform internal pressure $p_{\text {gas }}$ 
Fig. 14 shows the linear increases of the stress concentrations at the interior surface of a spherical hole in an elastic rock subjected to both the external uniform compression pressure $\sigma_{\mathrm{s}}$ and the internal gas pressure $p_{\text {gas }}$ with respect to the ratio $p_{\text {gas }} / \sigma_{\mathrm{s} \text {. }}$ It is evident that the hoop normal stress $\sigma_{\theta \theta}$ would become tensile (negative value) after $p_{\text {gas }} / \sigma_{\mathrm{s}} \geq 3$. Therefore, the following tensile or shear failure criteria may be adopted for local crack at the spherical hole.

$$
\begin{aligned}
& p_{\text {gasmintensile }} \geq 3 \sigma_{s}+2 \sigma_{\text {tensilestrength }} \\
& p_{\text {gas minshear }} \geq \sigma_{s}+\frac{4}{3} \sigma_{\text {shearstrength }}
\end{aligned}
$$

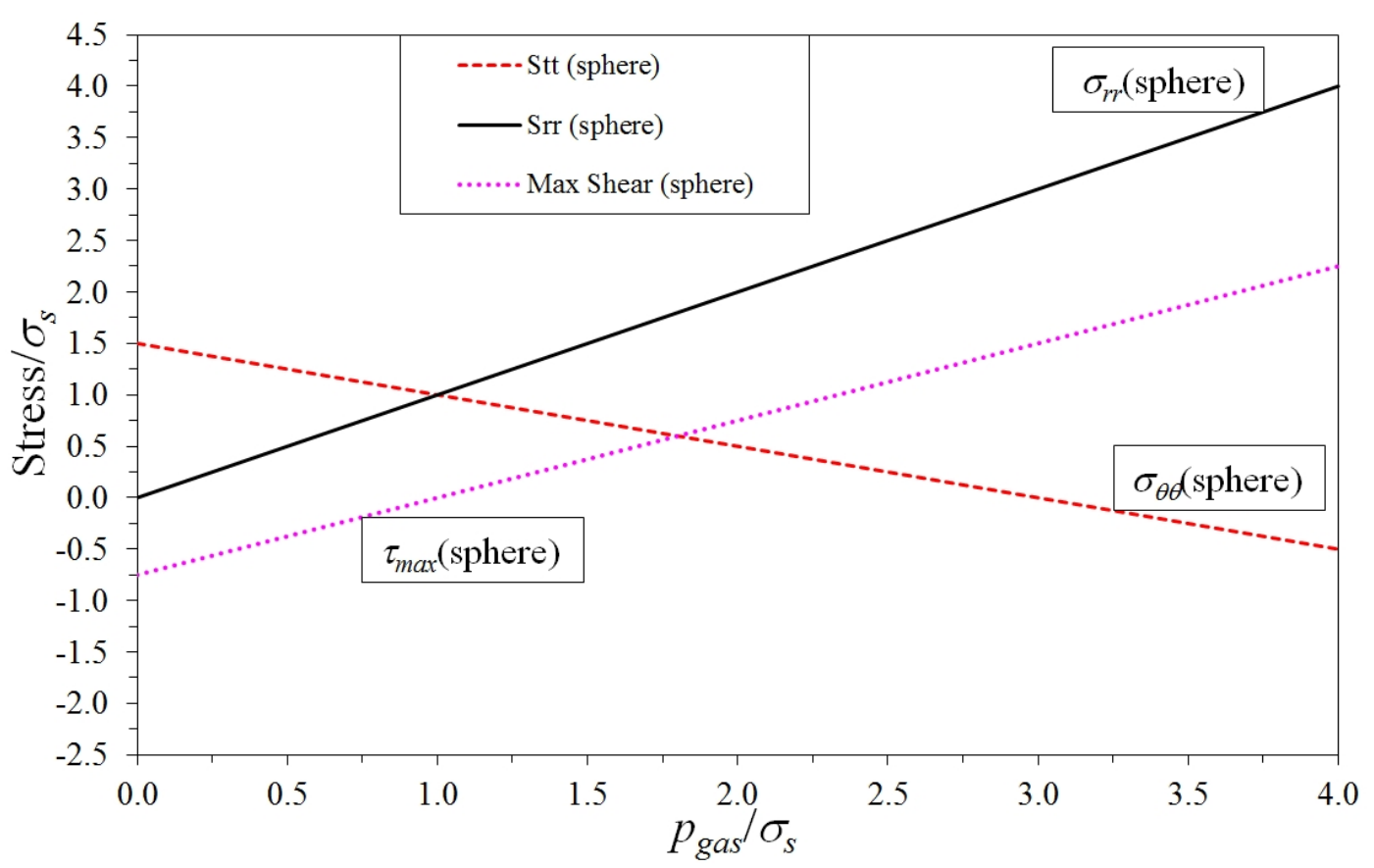

Fig.14 Stress concentrations at the interior surface of a spherical hole in an elastic rock subjected to both the external uniform compression pressure $\sigma_{\mathrm{s}}$ and the internal gas pressure $p_{\text {gas }}$ with respect to the ratio $p_{\text {gas }} / \sigma_{\mathrm{s}}$

\section{Governing equations of idealized gas for the internal gas loading}

Due to its rapid process of completion, an earthquake (or a tremor/shock) is an adiabatic process. Therefore, the migration and expansion of the compressed gas in the trap, cavern, fault and other rock discontinuities must also be an adiabatic process and follows the wellestablished governing equations of the idealized gas. Its volume $V_{\text {gas }}(X, Y, Z, 0)$, pressure $p_{\text {gas }}(X, Y, Z, 0)$ and temperature $T_{\text {gas }}(X, Y, Z, 0)$ at the time $t=0$ and at the location $(X, Y, Z)$ in the trap can have the following relationship with its volume $V_{g a s}(x, y, z, t)$, pressure $p_{\text {gas }}(x, y, z, t)$ and temperature $T_{\text {gas }}(x, y, z, t)$ at the time $t$ and at the location $(x, y, z)$ in the upper and lateral rock fault,

$$
p_{\text {gas }}(x, y, z, t)\left(V_{\text {gas }}(x, y, z, t)\right)^{\kappa}=p_{\text {gas }}(X, Y, Z, 0)\left(V_{\text {gas }}(X, Y, Z, 0)\right)^{\kappa}
$$




$$
\frac{T_{\text {gas }}(X, Y, Z, 0)}{T_{\text {gas }}(x, y, z, t)}=\left(\frac{p_{\text {gas }}(X, Y, Z, 0)}{p_{\text {gas }}(x, y, Z, t)}\right)^{1-1 / \kappa}
$$

where $\kappa>1$ is the gas specific heat ratio and depends on temperature. At the standard atmospheric pressure $p_{\text {gas }}^{\text {atmospheric }}(\approx 0.1 \mathrm{MPa})$, and a room temperature $25{ }^{\circ} \mathrm{C}, \kappa=1.66,1.41$ and 1.31 for helium, hydrogen and methane gases, respectively. $\kappa$ is assumed constant in equations (52) to (53).

As the gas migrates rapidly out of the trap and into the fault and voids in the upper and lateral rock mass, its $p_{\text {gas }}(x, y, z, t)$ decreases, its $V_{\text {gas }}(x, y, z, t)$ can increase and its $T_{g a s}(x, y, z, t)$ can decrease with time and location according to the equations (52) and (53). In particular, the gas volume can expand by 1000 to 5000 times. The gas density can be expressed as follows.

$$
\text { Density }_{\text {gas }}(x, y, z, t)=\frac{m_{\text {gas }}(x, y, z, t)}{V_{\text {gas }}(x, y, z, t)}
$$

where $m_{\text {gas }}(x, y, z, t)$ is the gas mass at the time $t$ and at the location $(x, y, z)$. At the standard atmospheric pressure $p_{\text {gas }}^{\text {atmosheric }}(\approx 0.1 \mathrm{MPa})$ and a room temperature $25{ }^{\circ} \mathrm{C}$, the methane gas density is $0.668 \mathrm{~kg} / \mathrm{m}^{3}$. In its deep trap, the methane gas density can be greater than 1000 $\mathrm{kg} / \mathrm{m}^{3}$ and up to $2000 \mathrm{~kg} / \mathrm{m}^{3}$.

Furthermore, during the adiabatic process of gas migration and expansion from the original location to the new location along the fault in the upper and lateral rocks, the work $W_{\text {gas }}(x, y, z, t)$ done by the compressed gas to the surrounding fault rocks can be expressed as follows,

$$
W_{\text {gas }}(x, y, z, t)=\frac{p_{\text {gas }}(X, Y, Z, 0) V_{\text {gas }}(X, Y, Z, 0)}{\kappa-1}\left[1-\left(\frac{p_{g a s}(x, y, Z, t)}{p_{\text {gas }}(X, Y, Z, 0)}\right)^{1-1 / \kappa}\right]
$$

The rapid migration and expansion of the train of a highly compressed gas mass in the fault zone would apply a moving dynamic load to the surrounding rocks. Such a moving dynamic loading in the interior of solid crustal rocks would form an initial-boundary value problem. The governing equations of elasto-dynamics, elasto-plastic dynamics and/or elasto-fracture dynamics can be used to solve the interactive responses of both the expanding and migrating of the compressed gas and the fracturing, lifting, moving and deforming (wave propagations) of the surrounding rock and soil solids. Specific results for the interactive responses will be reported in future publications.

\section{Analyses and discussions}

\subsection{Earthquake prediction and precursors}


The Reid hypothesis has been used as the foundation for earthquake prediction. The stress distributions in crustal rocks due to tectonic plate relative movement loadings have to following the prediction of the theories of elasticity, plasticity and fracture mechanics. Some of these elastic stress distributions are presented in the equations (1) to (5), (11) to 16), (22) to (24), (32) to (36) and (44) to (46). They evidently show that the local stress concentrations at the near field of faults, defects and caverns are well linked with the stress performance at the far field. In other word, although the focal depths of damaging earthquakes are of $10 \mathrm{~km}$ to $30 \mathrm{~km}$ below the ground surface, the elastic stress concentration and change at the near focal depth field should be reflected in the elastic stress at the far field such as the ground surface. However, such theoretical concept has encountered many failures when it is used for the prediction of next damaging earthquakes. The precursors that have developed and used according to this theoretical concept are not able to predict the next damaging earthquakes.

On the other hand, the stress distributions in crustal rocks due to the internal gas pressure loading also follow the theories of elasticity, plasticity and fracture mechanics. These elastic stress distributions presented in the equations (6) to (7), (17) to (21), (25) to (31), (37) to (43), and (47) to (51) clearly demonstrate that the local stress concentrations at the near field of faults, defects and caverns vanish or disappear quickly as the distance increasing. In other words, the local stress concentrations and build-up due to the internal gas pressure are delinked and decoupled with those tectonic stresses at the far field or ground surface. Therefore, the measurements at the ground surface cannot see or distinguish the change and build-up of the local stress concentrations induced by the internal gas pressure and mass at the deep ground. Therefore, earthquakes often suddenly occur without noticeable warnings. It is noted that this gas hypothesis and its associated precursors have not been used and developed for prediction of next damaging earthquakes so far. The author trusts that noticeable warnings and precursors are available if this gas hypothesis is adopted. The abnormal of methane gas in shallow ground with time and space can be a primary precursor for early prediction of next damage earthquakes [44].

\subsection{Rupture initiation at deep crustal rock}

It is clear that the tectonic stress state at the focal depth is a compressive state with three principal stresses of same or different values. The intermediate principal stress $\sigma_{2}$ is usually equal or similar to the vertical overburden stress due to gravity (ie., $\gamma_{\text {rock }} g h, \gamma_{\text {rock }}$ is rock density, $g$ is the gravitational acceleration, $h$ is depth to ground surface). Since rock can have high compressive strength, therefore, the rupture initiation of the crustal rocks at the focus is mainly due to shear failure according to the Reid hypothesis. The shear failure criteria in equations (3) to (5) may be applicable to such failure mode. However, it is definitely not easy for the crustal rocks to initiate and propagate such rapid shear rupture because of extremely high compressive normal stress acting on the shear plane. Furthermore, since the compressive tectonic stress state is present globally in the crustal rocks and the crustal rocks have many defects such as faults and beddings, such shear ruptures with sudden releases of huge 
amounts of rock elastic stress-strain energy would occur at many places if it could occur at one location.

On the other hand, the gas hypothesis can offer additional local stresses to the compressive global tectonic stress field. The additional local stresses can be in tension and can have high values to balance the compressive global tectonic stresses. Therefore, the combined stresses can be in tension. Consequently, tensile or shear ruptures and/or the rock fractures of the opening mode and shear ruptures of the in-plane and out-of-plane shear can be made possible along the rock discontinuities if they contain highly compressed natural gas mass. These discontinuities include faults, beddings, joints, foliations, fissures, contact zones, caverns and/or apertures. The shear and tensile rupture criteria in equations (7) to (10), (42) to (43) and (50) to (51) can be applicable and can be reached easily because the normal stress acting on the tensile/shear rupture plane can be small in compression or high in tension. The external uniform compressive stress $\sigma_{0}$ or $\sigma_{s}$ in equations (22) to (51) may be estimated using the following mean stress equation in association with the first stress invariant.

$$
\sigma_{s}=\frac{1}{3}\left(\sigma_{1}+\sigma_{2}+\sigma_{3}\right)
$$

Since the crustal rock materials have relatively lower values of tensile strength and fracture toughness, the internal dense gas pressure $p_{0}$ and/or $p_{\text {gas }}$ can have the following limits for initiation of tensile or shear ruptures in various rock defects from Griffith cracks to complete spherical caverns.

$$
\sigma_{s}\left(\text { or } \sigma_{3}\right) \leq p_{g a s} \leq 3 \sigma_{s}
$$

\subsection{Earthquake energy and its release}

At any point in a rock solid with the elastic principal stresses $\sigma_{1}(\mathbf{x}, t), \sigma_{2}(\mathbf{x}, t)$ and $\sigma_{3}(\mathbf{x}, t)$ and the elastic modulus $E$, the elastic stress-strain energy intensity $W_{\text {total }}$ can be expressed as follows.

$$
W_{\text {total }}=\frac{1}{2 E}\left[\sigma_{1}^{2}+\sigma_{2}^{2}+\sigma_{3}^{2}-2 v\left(\sigma_{1} \sigma_{2}+\sigma_{2} \sigma_{3}+\sigma_{3} \sigma_{1}\right)\right]
$$

Therefore, the total elastic stress-strain energy $W_{\text {тотАL }}$ held in an elastic solid of volume $V_{\text {rock }}$ can be estimated with the following integration over the rock volume.

$$
W_{\text {TOTAL }}=\iiint_{V_{\text {rock }}} W_{\text {total }} d V \text {. }
$$

According to the Reid hypothesis, an earthquake releases a portion of the total elastic stressstrain energy that is previously and gradually stored in the rock materials along a fault. Therefore, the released earthquake may be expressed as

$$
\text { The released earthquake energy }=W_{\text {TOTAL }}^{\text {before }}-W_{\text {TOTAL }}^{\text {after }} \text {. }
$$

where $W_{\text {TOTAL }}^{\text {before }}$ and $W_{\text {TOTAL }}^{\text {after }}$ can be estimated using equations (58) and (59) in association with the elastic tectonic rock stresses before and after an earthquake respectively. For a positive 
energy release, an earthquake must cause some definite reductions in the existing tectonic stresses of the crustal rocks (or stress drops $\Delta \sigma$ ).

Because of difficulty in determining the tectonic stress distribution before and after an earthquake, the following equations have been used to estimate the crustal rock energy released by an earthquake [30] in modern seismology.

$$
\mathrm{M}_{0}=\mu \overline{\mathrm{D}} A,
$$

where $\mathrm{M}_{0}$, the scalar seismic moment with the unit $\mathrm{Nm}$ (or Joule), is a measure of the irreversible inelastic deformation in the rupture area. $\mu$ is the rigidity or shear modulus of the rock mass (GPa). $\bar{D}$ is the average final displacement after the rupture (m), is related to the stress drop $\Delta \sigma$. $A$ is the surface area of the rupture $\left(\mathrm{m}^{2}\right)$.

However, according to the elastic stresses due to the external loading in equations (11) to (16), (22) to (24), (32) to (36) and (44) to (49), the stress concentrations due to local defects are local and can be reduced to the global tectonic stresses at some short distance. In addition, the crustal rocks have many defects at different locations. The external global loading can cause many local stress concentrations and possible cracks. It can produce many similar local stress concentrations over large areas. If brittle rupture failure occurred at one rock defect, it would be able to occur at many other rock defects with similar stress centration conditions. Hence, the relative series of the earthquake occurrences at a tectonic plate region such as Northern China could be regulated and predicted using methods of applied mechanics [21-25]. Such effort has not yet resolved the problem of earthquake prediction.

On the other hand, according to the Griffith fracture mechanics, the gas expansion work in the interior of the fault rocks to cause the brittle fracture and crack propagation is relatively very small. Therefore, a large portion of the gas work can be used to overcome the rock gravity potential energy and to apply to the rock movement, deformation and vibration that produce the four types of seismic waves in the rocks to the far fields. The gas rapid expansion can absorb heat from the surrounding rocks and soils so that the earthquake process is a cooling process immediately after the time of the initial rock fracture. The total work $W_{\text {gas }}^{\text {total }}$ that the compressed gas can apply to the surrounding rocks and soils can be estimated with the following equation where the gas pressure is reduced to the standard atmospheric pressure at the ground level.

$$
W_{\text {gas }}^{\text {total }}=\frac{p_{\text {gas }}(X, Y, Z, 0) V_{\text {gas }}(X, Y, Z, 0)}{\kappa-1}\left[1-\left(\frac{p_{\text {gas }}^{\text {atmoshperic }}}{p_{\text {gas }}(X, Y, Z, 0)}\right)^{1-1 / \kappa}\right]
$$

It can be argued that the total released earthquake energy is equal to the total volumetric expansion energy of the compressed gas mass escaped from its trap in the deep fault ground. The volumetric expansion energy increases proportionally with the increases in the initial dense gas pressure and escaped dense gas volume. According to equations (6) to (10), (25) to (31), (42), (43), (50), (51), (56) and (57), it is evident that the dense gas pressure for breaking and rupturing crustal rocks is controlled by the compressive crustal stress. A larger 22-34 
compressive crustal stress would have a larger dense gas pressure to break and rupture the crustal rocks and subsequently a larger earthquake. A smaller compressive crustal stress would have a smaller dense gas pressure to break and rupture the crustal rocks and subsequently a smaller earthquake.

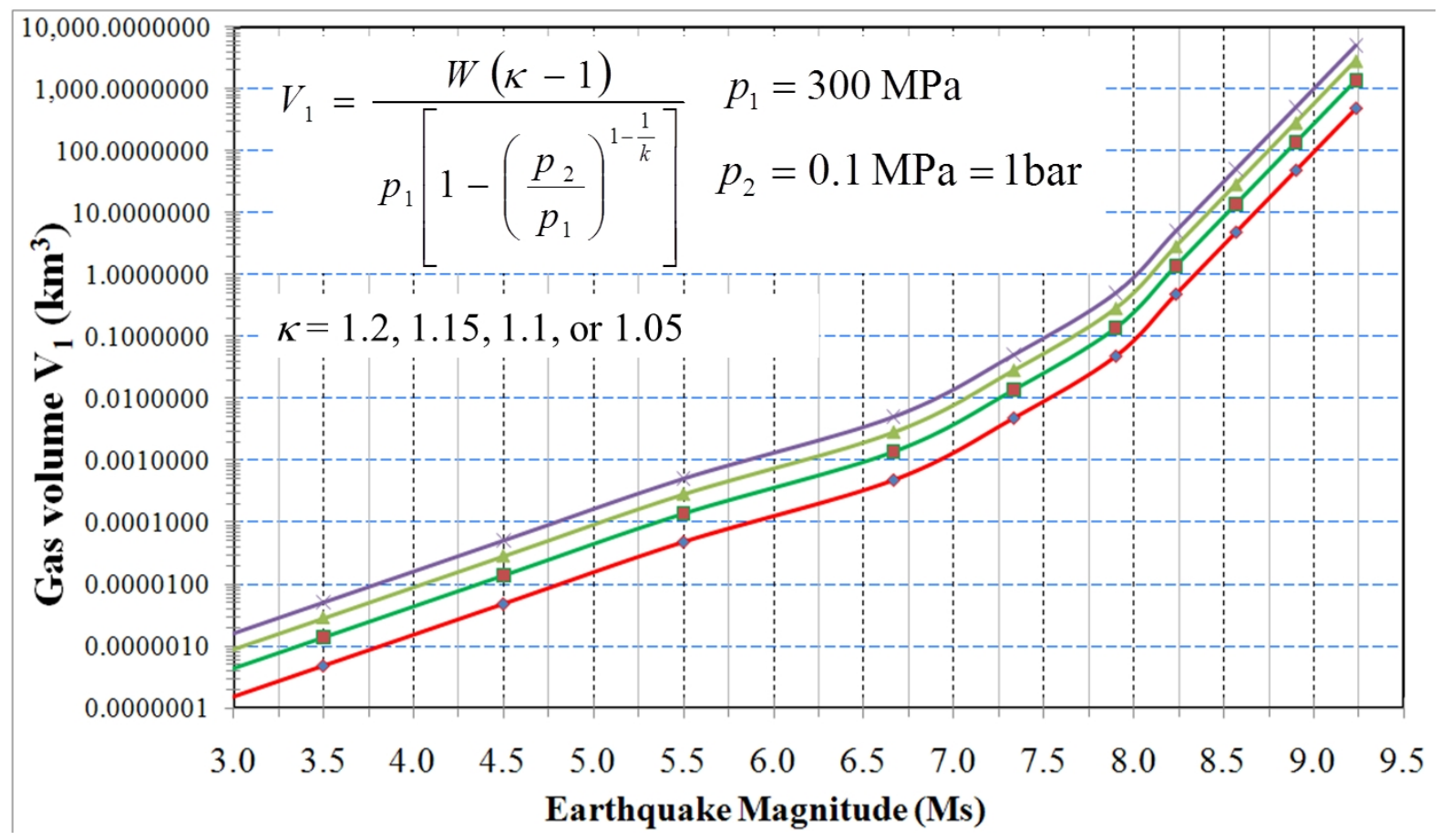

Fig. 15 Relationship between earthquake magnitude (Ms) and its causing dense gas volume estimated with the equal assumption of gas expansion energy and earthquake energy [13].

Accordingly, the radiated seismic strain energy calculated from the recorded seismic waves can be equal to or slightly less than the total gas expansion energy. Then, the earthquake magnitude $\left(\mathrm{M}_{\mathrm{S}}\right)$ from seismographs [30] can be used to estimate the volume of the escaped dense gas mass with the trap pressure (62). The results are given in Fig. 15. Accordingly, it is estimated that the escaped dense gas mass of volume about $40 \mathrm{~km}^{3}$ and pressure $300 \mathrm{MPa}$ caused the 2011 off the Pacific Coast of Tohoku Earthquake $\left(M_{s} 9.0\right)$. The escaped dense gas mass of volume about $1 \mathrm{~km}^{3}$ and pressure $300 \mathrm{MPa}$ caused the 2008 Wenchuan Earthquake $\left(\mathrm{M}_{\mathrm{s}} 8.0\right)$.

\subsection{Changes of tectonic stresses and escaped gas pressure with crustal depth}

In general, the global tectonic stresses increase linearly as the crustal depth increases or decrease linearly as the crustal depth decreases, as shown in Fig. 16. On the other hand, it is assumed that the dense (methane) gas is trapped below deep rock fault of $10 \mathrm{~km}$ to $30 \mathrm{~km}$ below the ground surface and has a high pressure of several hundred MPa. Once the dense gas fractures the trap weak rocks, part of the dense gas mass would quickly escape the trap and forcefully fly upward and laterally along fault weak zones. Simultaneously, the gas pressure would reduce and its volume would increase according to the confinements \& 
pressures of the flow channel surrounding rocks. According to equations (52) to (55), the pressure, volume and temperature of the escaped gas mass have the relationships governed by the equations (52) to (53). Fig. 16 also shows a possible pressure reduction of the escaped dense gas mass as its depth to the ground surface decreases, where the dense gas is originally trapped at $14 \mathrm{~km}$ below the ground surface and has a pressure $300 \mathrm{MPa}$.

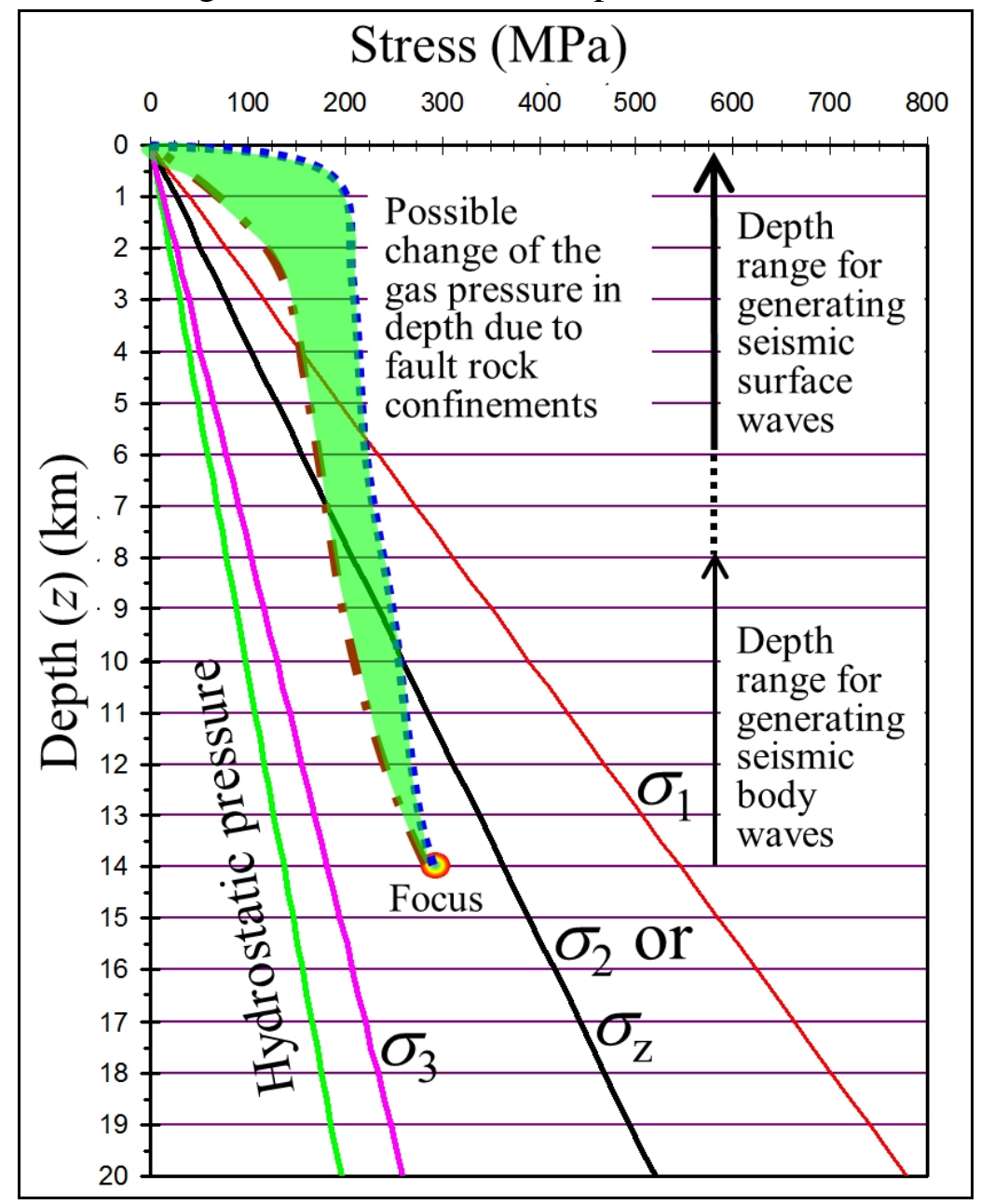

Fig. 16 Possible changes of in-situ tectonic stresses and the escaped gas pressure with its decreasing in depth

It is evident that the depth reductions of the tectonic stresses and the escaped gas pressure have different patterns. The volumetric expansion and enlargement of the escaped dense gas mass are confined and constrained by the crustal rock mass and its compressive tectonic stresses. They increase slowly during the initial period of time as the escaped gas mass rapidly migrates and become large during the later stage as the escaped gas mass migrates to shallow depth, as shown in Fig. 17. Correspondingly, the pressure reduction of the escaped gas mass during its initial rapid upward and lateral migration and flow would also be slow and can be much slower than the linear reductions of the tectonic stresses $\sigma_{1}(\mathbf{x}, t), \sigma_{2}(\mathbf{x}, t)$ and $\sigma_{3}(\mathbf{x}, t)$ with their depth, as shown in Fig. 16. Consequently, the pressure $p_{\text {gas }}(x, y, z, t)$ of the 
escaped gas mass can become larger and larger than its surrounding tectonic stresses $\sigma_{\mathrm{s}}$, $\sigma_{1}(\mathbf{x}, t), \sigma_{2}(\mathbf{x}, t)$ and $\sigma_{3}(\mathbf{x}, t)$ as it rapidly migrates upward.

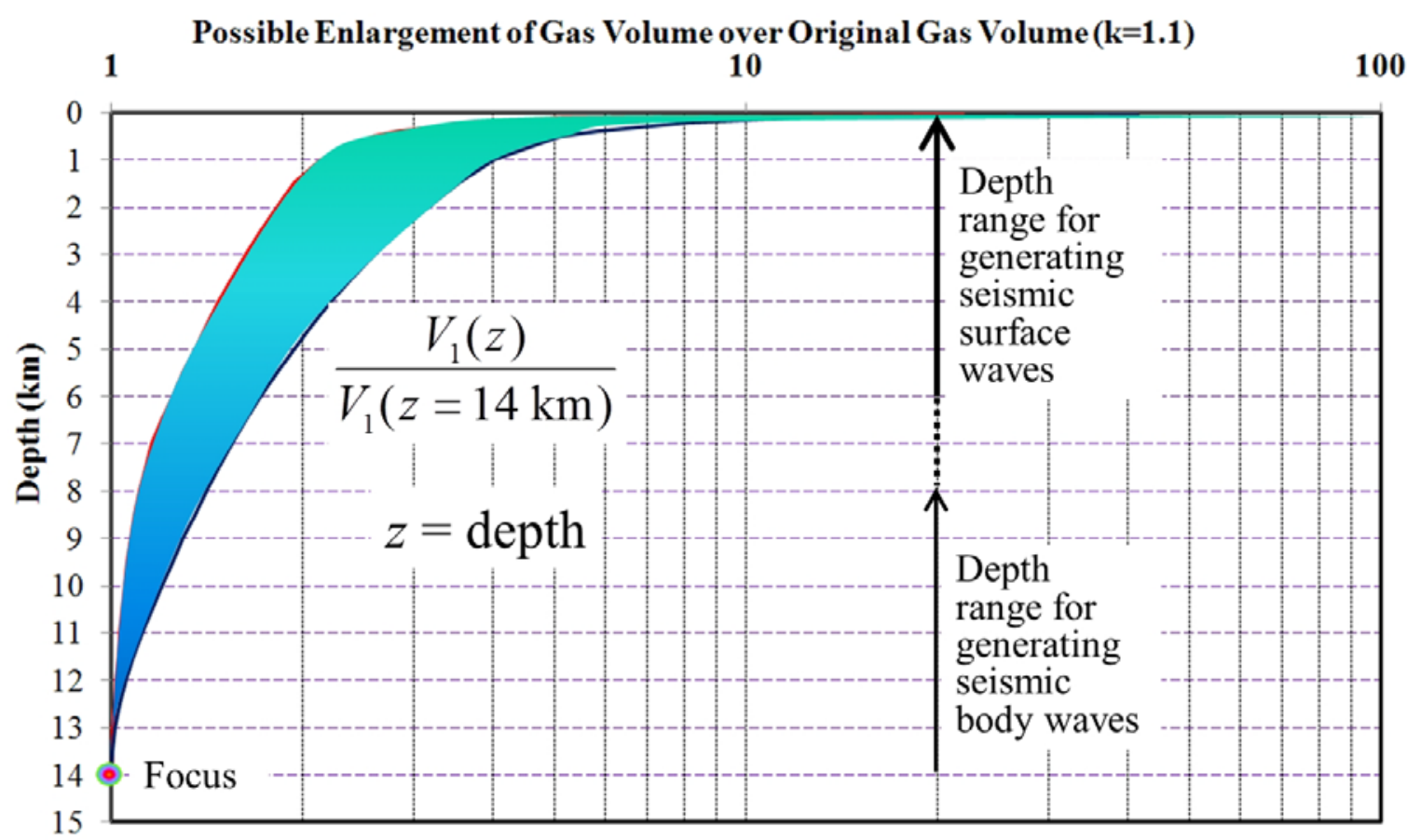

Fig. 17 Possible change for volumetric expansion ratio of escaped gas mass with its decreasing in depth

Using the rupture criteria in equation (57), the fast upward and lateral migration of the escaped gas mass would become more and more powerful in expanding and shearing the crustal rock mass to rupture and deform. In the meantime, the escaped gas mass can expand substantially so that much large ground areas at shallow depth can be affected or damaged by the expanding power of the escaped dense gas mass. The volumetric expansion of the escaped dense gas can reach to huge volume of several hundred to several thousand times than its original volume (Fig. 17). Furthermore, the temperature of the escaped gas mass can be dropped substantially, which can cool the nearby crustal rocks and crack tips. Such reduction of the crack tip rock temperature can make the rock at front of the crack tip more brittle, which reduces the rock toughness and makes crack initiation and propagation easier. On the other hand, the drop in the surrounding rock temperature can increase the rock modulus and compressive strength, which can result in concentrations of the escaped dense gas migration and flow along some main fault channels in the deep ground.

This interaction between the rapid migration and expansion of the escaped dense gas and its crustal rock mass generates the elastic seismic waves. At the deeper depth immediately above the escaping focus, the migration and expansion of the escaped dense gas mass is highly controlled by the crustal rocks with higher compressive tectonic stresses, which generates the 
body waves (P- and S-waves) including the ground sounds. As its depth decreases, the escaped dense gas mass becomes more and more powerful and actually controls the ruptures and deformation of the crustal rock mass with smaller compressive tectonic stresses, which generates the surface waves (Love and Rayleigh waves). The ratio of the pressure of the escaped dense gas mass at the depth $z$ over the vertical rock overburden gravity stress at the same depth $z$ can be increased from the less than 1.0 value at the original depth to several hundreds, as shown in Fig. 18. Consequently, the wave amplitudes of the seismic surface waves decay strongly as the depth to the ground surface increases.

\section{Ratio of Escaped Gas Pressure over Rock Vertical Stress}

0.1

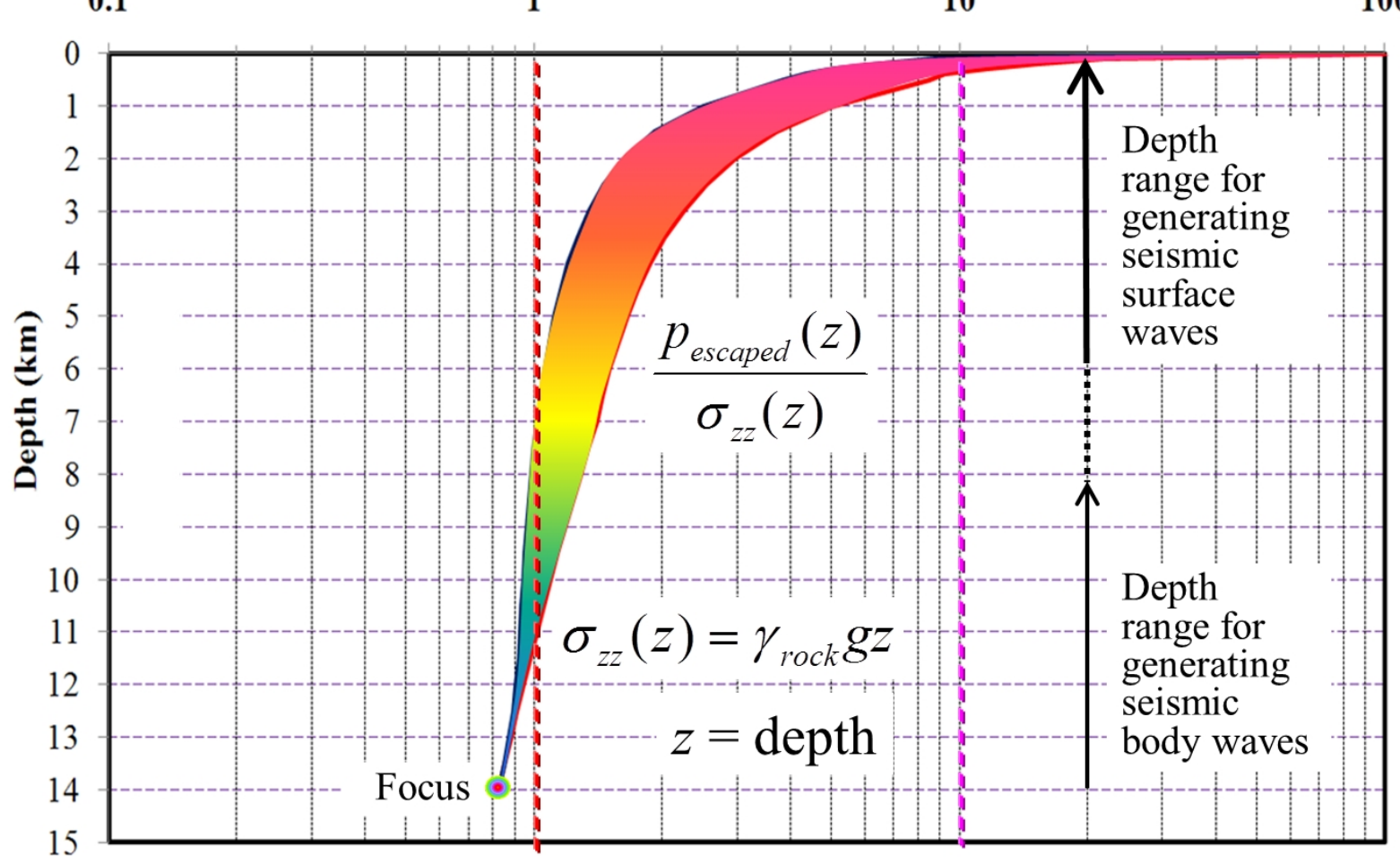

Fig. 18 Change of the ratio of the escaped gas mass pressure over the vertical rock overburden stress with its decreasing in depth

The escaped dense gas mass would lose its power in causing the ground deformation, ruptures, and vibrations and waves once it emits into the sky or enters into voids and caverns (reservoirs) where its volume and pressure are well balanced by the surrounding rock mass and its tectonic stresses. At this moment, the ground tremor vanishes quickly. Because of extremely high migration and flow speeds, the escaped dense gas mass would quickly flow and expand into the very high sky. It would cause sudden substantial changes in the atmosphere. It would result in the sudden drops of the air temperature at the epicenter and some convective flows in the atmosphere. Subsequently, the sky would change its color and become cloudy. Heavy rainfall or snow would occur several hours after the earthquake occurrence. On the other hand, if the escaped dense gas mass flows and migrates into thick 
waters in lakes or oceans, its rapid migration and expansion power can cause the entire water to move and flow (i.e., tsunamis).

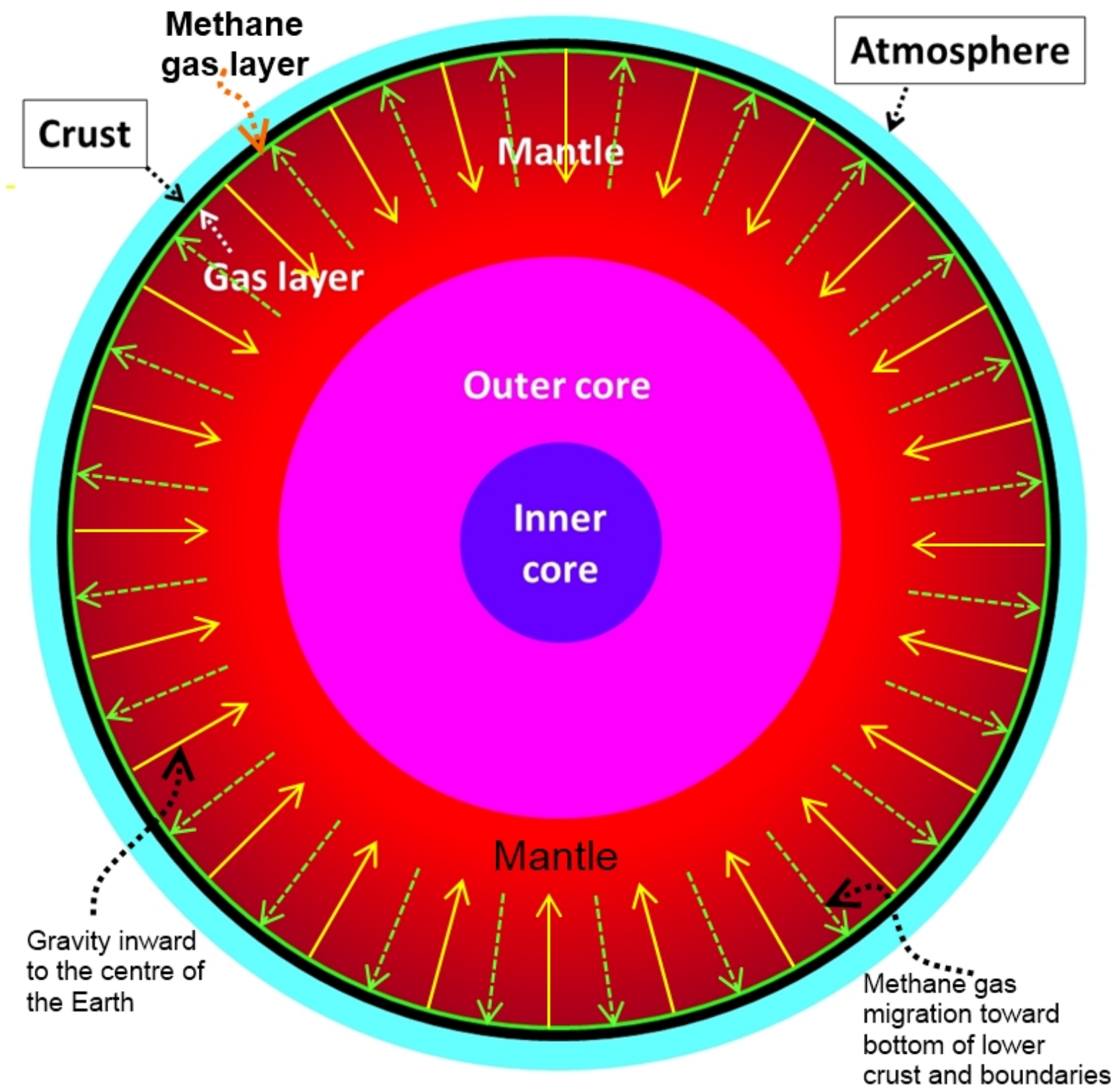

Fig. 19 A thin spherical dense methane gas layer exists as the gap mass between the crust and the mantle, the dense gas mass is produced in the mantle and core and migrates outward to the bottom of the lower crust rock in high compression (modified after [14])

\subsection{Origin, primary and secondary traps, and leaking zones of the dense methane gas}

For many years, release of pressurized gas that was observed before, during and/or after an earthquake has been recognized as an outcome, instead of the cause, of the earthquake. Consequently, many people have overlooked the possibility of dense gas cause of earthquakes. This possibility has not been investigated well. It is shown in the above that the combined loading of internal dense gas and external tectonic stress is highly and easily possible to cause earthquake. On the other hand, our human beings still do not know much 
about the interior of the Earth. The huge mass of high temperature and high pressure forming the mantle and core of the Earth can have the ability to generate large amount of methane gas every day. The methane gas generated in the mantle and core has to migrate and flow upward and accumulate beneath and in the lower crust according to the second law of thermodynamics, where the lower crustal rock in high compression forms the primary spherical trap (see Fig. 19) [14]. The spherical dense gas layer is an ideal foundation to flexibly support, uplift and float the spherical crustal rocks. So, the crustal rocks can be stable and integrity over vast areas to form huge plates and basins and can have relative hoop movement and drifts. It is also an ideal insulation layer to prevent the crust rock from melting by the hot mantle materials and also to prevent the heat of the mantle/cores from leaking into the crust rocks and the atmosphere. As a result, the mantle/cores can keep their hot temperatures and the crust can keep their solid rocks for millions to billions years. It is estimated that the thin gas layer can have the thickness variable from several hundred meters beneath oceanic crust to a few kilometers beneath mountainous plateau continental crust. Its density is from 1000 $\mathrm{kg} / \mathrm{m}^{3}$ to $2000 \mathrm{~kg} / \mathrm{m}^{3}$. Accordingly, the dense methane gas mass forming the thin spherical layer can be 10 to 240 times of the air mass $\left(5.148 \times 10^{18} \mathrm{~kg}\right)$ forming the atmosphere (Fig. 20).

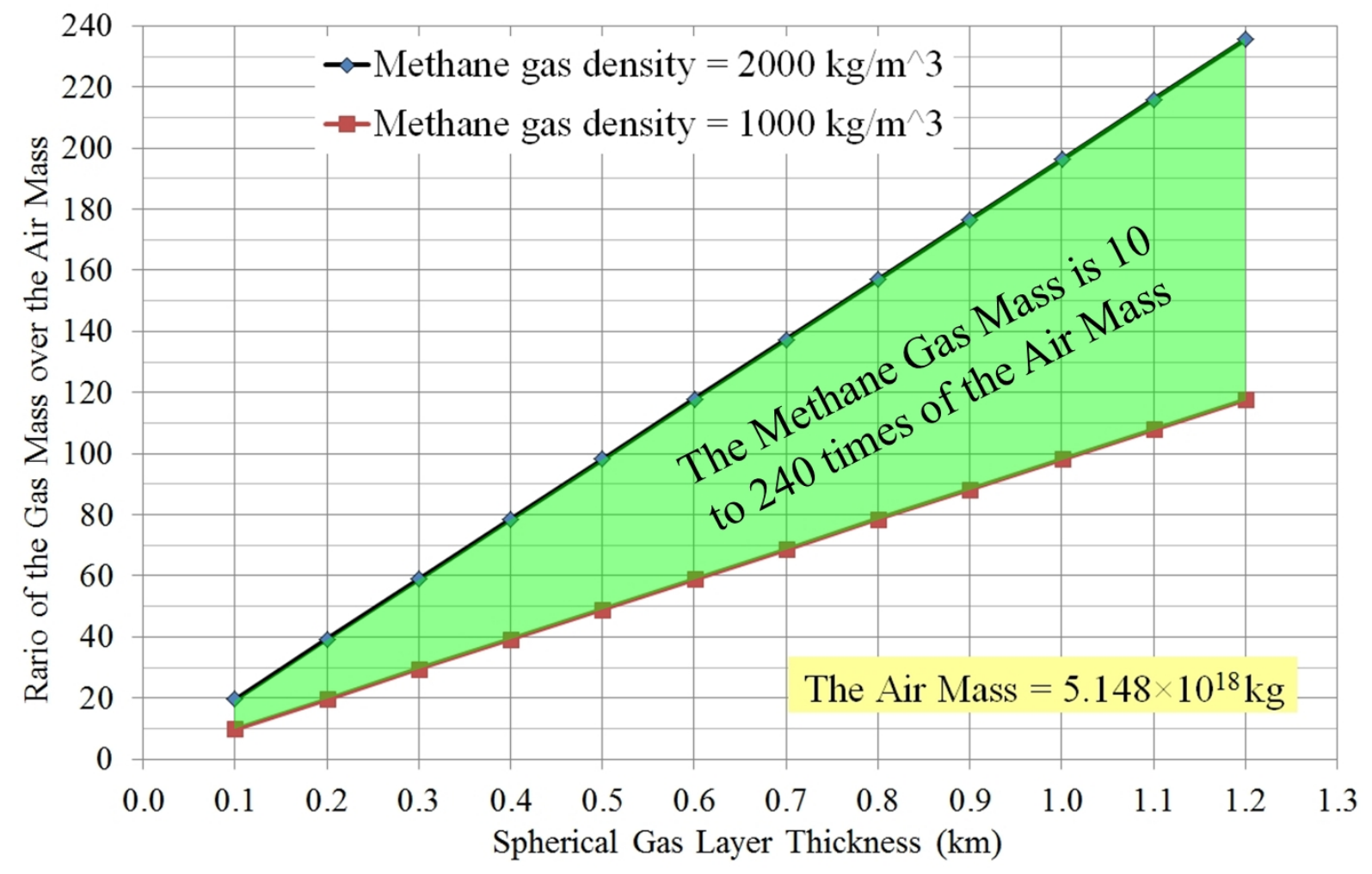

Fig. 20 Ratio of the dense methane gas mass forming the thin spherical layer over the air mass forming the atmosphere with the thin gas layer thickness and density.

Hence, there are enough mantle/core dense gas masses to cause earthquakes frequently and huge earthquakes periodically. In particular, the boundaries of tectonic plates consist of deep faults and unconformity contacts of rock masses, where localized and irregular gaps, weak zones, and apertures can be present between the two contacted plate rock masses. 
Accordingly, the mantle/core dense gas would like to further migrate and flow into and accumulate and store in these gaps, weak zones and apertures. With time, more and more dense gas masses would accumulate and store at the plate boundaries and build up their pressure and expanding power in their traps along the plate boundaries. Once the internal dense gas pressure reaches the critical value, it would rupture the fault rocks at the boundaries, and a certain amount of the dense gas mass would escape its traps, which would cause an earthquake. This can be used to explain the facts that most earthquakes occur at the boundaries of tectonic plates and earthquakes can re-occur every few years. Accordingly, the tectonic plate boundaries are the weak belts for leaking dense mantle/core methane gas from the primary spherical crust rock trap. Part of the dense gas leaked and escaped from the deep boundary traps would further migrate and flow into either the secondary traps in upper crust rock masses to form gas/oil reservoirs. The other part would emit into the sky.

Consequently, the sedimentary rock basins in the upper crust adjacent to the tectonic plate boundaries can become the giant gas and oil fields. The gas and oil reservoirs in the sedimentary rock basins are within $8 \mathrm{~km}$ deep in the upper crust. Their adjacent tectonic plate boundaries have long and deep faults of hundreds to thousand $\mathrm{km}$ in length and 20 to $30 \mathrm{~km}$ in depth. Mann et al [44] gave a detailed description of 877 giant oil and gas fields around the world. They classified the tectonic setting of the 877 giants in these regions using six simplified classes of the tectonic setting for basins in these regions: (a) 304 giants in continental passive margins fronting major ocean basins; (b) 271 in continental rifts and overlying sag or "steer's head"' basins; (c) 173 in collisional margins produced by terminal collision between two continents; (d) 71 in collisional margins produced by continental collision related to terrane accretion, arc collision, and/or shallow subduction; (e) 50 in strikeslip margins; (f) 8 in subduction margins not affected by major arc or continental collisions. A majority of these tectonic settings have occurred many earthquakes. The most typical examples are the California basin in USA and the Sichuan basin in China.

\section{Concluding remarks}

The conventional hypothesis for the cause of tectonic earthquakes is the active fault elastic rebounding hypothesis proposed by Professor H.F. Reid after his investigation of the 1906 California Earthquake [6-7] and has been widely accepted and used for earthquake prediction since the establishment of the plate tectonic theory in 1950s to 1960s [30]. Based on this Reid hypothesis, the earthquake mechanism can be modeled with the external loading system, where the crustal rocks with interlocked fault crack is subjected to the external loading of relative tectonic plate movements and gravity. The current consensus in seismology and earth science communities that earthquake is unpredictable with present technology, however, may have demonstrated that this conventional hypothesis needs to be revisited and refined.

Therefore, the author has put forward a dense methane gas hypothesis for the cause of tectonic earthquakes since his active and intensive investigation of the 2008 Wenchuan 
Earthquake from May to August 2008. This dense gas hypothesis is a refinement of the Reid hypothesis because it adds a dense gas mass in the deep crustal rock faults. Because of its high pressure, the dense gas mass in the interior of the deep crustal rock faults can generate a secondary and local stress and strain field in addition to the tectonic stress and strain field generated by the external loading of relative tectonic plate movements. Because of some geological, geophysical and geochemical reasons, the gas mass in the interior of the deep crustal rock faults can increase its pressure and/or mass [14]. The local stress concentrations due to ever increasing dense gas mass pressure can become high and high. The tectonic stress and strain field provides confinements and constraints to the change of the dense gas mass in the interior of deep crustal rock faults or defects. Eventually, the dense gas mass can cause the deep crustal fault rocks to rupture in the forms of opening and shearing modes. Subsequently, a part of the dense gas mass can escape its trap and rapidly flow and migrate via the fault channels upward and laterally. The expanding power of the escaped gas mass further causes seismic waves and ground damages.

Five elastic stresses in elastic solids with some idealized faults and caverns are presented to illustrate the similarities and differences of the stress fields and the possible rupture failure modes in association of the external tectonic plate loading alone and the combined loading of external tectonic plate loading and the internal dense gas mass loading. The results have shown that any changes in the local stress concentrations due the external loading alone can be reflected and noticed in the corresponding stresses at the far field. On the other hand, any changes in the local stress concentrations due to the internal gas loading cannot be observed and distinguished in the tectonic stress field at the far distance. These theoretical results can be used to well explain the consensus of earthquake unpredictability with present technology.

Furthermore, the results have shown that the external tectonic loading alone can only cause shear ruptures in crustal fault rocks with high compressive stresses and such shear rupture or frictional failure is also difficult to occur because its shear plane has extremely high compressive normal stress. The combined loading can cause not only the shear ruptures but also tensile ruptures in crustal fault rocks and such shear and tensile ruptures are much easier to occur since its rupture plane can have very low compressive or even high tensile normal stress. A larger compressive crustal stress on the deep faults would need a higher dense gas pressure to break and rupture the crustal fault rocks again and subsequently a larger earthquake, and vise visa.

These theoretical results in applied mechanics and the governing laws of idealized dense gas are further used to examine and explain the rupture initiation of earthquakes, the ground shocking process, and the earthquake energy. It is argued that the earthquake energy is the volumetric expansion energy of dense gas mass escaped from the deep traps along crustal rock faults. The migration and expansion of the escaped dense gas mass in the crustal rock faults and defects cause the seismic body waves, the ground sounding, the seismic surface waves, the ground co-seismic ruptures and damages. Its rapid migration and expansion in 
thick water cause tsunamis in lakes and oceans. Its rapid migration and expansion in the atmosphere cause the sky to become cloudy and the temperature to drop down.

If this gas cause hypothesis of earthquakes is correct, the gas and oil mass in the 877 giants and other unknown reservoirs are re-chargeable and re-fillable. In other words, the methane gas and its chemical changes in the upper crust rock masses are deeply originated and constantly produced in the mantle and core of the Earth. They are migrated from the primary storage trap of the thin spherical dense gas layer separating the mantle and crust, and then stored in the secondary traps at upper crustal rock mass.

\section{Acknowledgements}

The author thanks many friends and colleagues for their invaluable advices, assistances, discussions, information, data and supports during his independent investigations of the nature of earthquakes and the Earth system. He also thanks the two reviewers and Professor Jacqueline Li, Guest-Editor for this special issue of Acta Mechanica for their comments to have improved the paper presentation.

\section{References}

1. Chen, Q.F., Wang, K.L.: The 2008 Wenchuan Earthquake and earthquake prediction in China. Bull. Seismol. Soc. Am. 100(5B), 2840-2857 (2010)

2. Hough, S.E.: Predicting the Unpredictable, the Tumultuous Science of Earthquake Prediction. Princeton University Press, New Jersey. p. 260 (2010)

3. Normile, D.: Devastating earthquake defied expectations. Science. 33, 1375-1376 (2011)

4. Monastersky, R.: Giant shock rattles ideas about quake behavior. Nature. 471, 274 (2011)

5. Geller, R.J.: Shake-up time for Japanese seismology. Nature. 472, 407-409 (2011)

6. A.C. Lawson, The Mechanics of the Earthquake, The California Earthquake of April 18, 1906, Report of the State Earthquake Investigation Commission, Vol.1, Parts I and II, Carnegie Institution of Washington, Washington, D.C., USA. p. 451 (1908)

7. H.F. Reid, The Mechanics of the Earthquake, The California Earthquake of April 18, 1906, Report of the State Earthquake Investigation Commission, Vol.2, Carnegie Institution of Washington, Washington, D.C., USA. p.192 (1910)

8. Yue, Z.Q.: What caused the catastrophic landslides during the May 12 Wenchuan Earthquake in Sichuan, China?. Abstract Proceedings of the 12th Int. Conf. of Int. Association for Computer Methods and Advances in Geomechanics (IACMAG). October 1-6, Goa, India: 135 (2008) 
9. Yue, Z.Q.: The source of energy power directly causing the May 12 Wenchuan Earthquake: Huge extremely pressurized natural gases trapped in deep Longmen Shan faults. News Journal of China Society of Rock Mechanics and Engineering, 86 (2009 (2)), 45-50 (2009)

10. Yue, Z.Q.: Features and mechanism of coseismic surface ruptures by Wenchuan Earthquake. Rock Stress and Earthquake. ed. Furen Xie, Taylor \& Francis Group, London, ISBN 978-0-415-60165-8. 761-768 (2010)

11. Yue, Z.Q.: Natural gas eruption mechanism for earthquake landslides: illustrated with comparison between Donghekou and Papandayan Rockslide-debris flows. Earthquakeinduced Landslides. eds., K. Ugai et al., Springer-Verlage Berlin. Chapter 51, 485-494 (2013)

12. Yue, Z.Q.: On incorrectness in elastic rebound theory for cause of earthquakes. Proceedings of the 13th International Conference on Fracture. Beijing. Paper No. S20-003 of Session S20, 1-10 (2013)

13. Yue, Z.Q.: On nature of earthquakes with cause of compressed methane gas expansion and migration in crustal rocks. Poromechanics V: Proceedings of Fifth Biot Conference on Poromechanics. Eds. C. Hellmich et al, ISBN 978-0-7844-1299-2, ASCE, Vienna, pp. 507-516 (2013).

14. Yue, Z.Q.: Why our Earth's crust not quiet? Global View of Engineering Geology and the Environment, Proceedings of International Symposium \& $9^{\text {th }}$ Asian Regional Conferences of IAEG, Editor Wu, F. and Qi S. CRC Press, ISBN 9781138000780, September 24-25, Beijing, pp.43-50 (2013)

15. Scholz, C.H.: The Mechanics of Earthquake and Faulting. Cambridge University Press, Cambridge. p.439 (1990)

16. Rice, J.R.: The mechanics of earthquake rupture. Physics of the Earth's Interior (Proc. International School of Physics 'Enrico Fermi', Course 78, 1979: eds. A.M. Dziewonski and E. Boschi), Italian Physical Society and North-Holland Publ. Co., Bologna, Italy, 555-649 (1980)

17. Li, V.C., Rice, J.R.: Pre-seismic rupture progression and great earthquake instabilities at plate boundaries. J.f Geophys. Res. 88, 4231-4246 (1983)

18. Tse, S.T., Rice, J.R., Crustal earthquake instability in relation to the depth variation of frictional slip properties. J. Geophys. Res. 91, 9452-9472 (1986)

19. Rice, J.R., Ben-Zion Y.: Slip complexity in earthquake fault model s. Proc. Natl. Acad. Sci. USA. 93, 3811-3818 (1996)

20. Rice, J.R.: Heating and weakening of faults during earthquake slip. J. Geophys. Res. Solid Earth. 111(B05311), 1-29 (2006) 
21. Wang, R., He G.Q., Yin, Y.Q., Cai, Y.E.: A mathematical simulation for the pattern of seismic transference in North China. Acta Seismological Sinica. 2(1), 32-42 (1980) (in Chinese)

22. Wang, R.: A short note on the inversion of tectonic stress fields. Tectonophysics. 100, 405-411 (1983)

23. Wang, S.M., Wang, R.: Joint inversion of the kinematics and dynamics of the North American plate. Tectonophysics. 302, 173-201 (1999)

24. Ma J., Zhang, B.T., Yi, S.R.: Preliminary study on the evolution of strain field near locked region of a fault. Seismology and Geology. 1(3), 47-55 (1979) (in Chinese)

25. Ma, J., Xu, X.Q.: Experimental study of recurrence interval and the ratio of co-seismic to aseismic displacement. Earthquake. 1989(01), 10-18 (1989) (in Chinese)

26. Ma, J. Uncertainty of the earthquakes and earthquake mechanism and seismic triggering effect of instantaneous factors. Chinese Journal of Nature. 32(6), 311-313, 318 (2010) (in Chinese)

27. He, C.R., Zhou, Y.S., Ma, J.: Tohoku Off-Pacific-Coast megaquake: another lesson from nature to mankind. Chinese Journal of Nature. 33(6), 63-69, (2011) (in Chinese)

28. Gilbert, F.: Excitation of the normal modes of the earth by earthquake sources. Geophysical Journal of the Royal Astronomical Society. 22, 223-226 (1970)

29. Aki, K., Richards, P.G.: Quantitative Seismology, $2^{\text {nd }}$ ed. University Science Books, Sausalito, California. p. 700 (2002)

30. Bormann, P. (Ed.): New Manual of Seismological Observatory Practice (NMSOP-2), IASPEI. GFZ German Research Centre for Geosciences, Potsdam. (2002)

31. Ji, C., Wald, D.J., Helmberger, D.V.: Source description of the 1999 Hector Mine, California, Earthquake, part I: wavelet domain inversion theory and resolution analysis. Bull.Seismol. Soc. Am. 92(4), 1192-1207 (2002)

32. Ji, C., Wald, D.J., Helmberger, D.V.: Source description of the 1999 Hector Mine, California, Earthquake, part II: complexity of slip history. Bull.Seismol. Soc. Am. 92(4), 1208-1226 (2002)

33. Xu, L.S., Chen, Y.T.: Temporal and spatial rupture process of the great Kunlun Mountain Pass earthquake of November 14, 2001 from the GDSN long period waveform data. Science in China Series D-Earth Sciences. 48(1), 112-122 (2005)

34. Parsons, T., Ji, C., Kirby, E.: Stress changes from the 2008 Wenchuan earthquake and increased hazard in the Sichuan basin. Nature. 454, 509-510 (2008)

35. Suzuki, W., Aoi, S., Sekiguchi, H., Kunugi, T.: Rupture process of the 2011 Tohoku Oki mega - thrust earthquake (M9.0) inverted from strong - motion data. Geophys. Res. Lett. 38, L00G16, 1-6 (2011) 
36. Reches, Z., Lockner, D.A.: Fault weakening and earthquake instability by powder lubrication. Nature. 467, 452-455 (2011)

37. Lockner, D.A., Morrow, C., Moore, D., Hickman, S.: Low strength of deep San Andreas fault gouge from SAFOD core. Nature. 472, 82-85 (2011)

38. R. X. Song (Editor-in-Chief), Album of the Kunlun Pass W. Ms 8.1 Earthquake, China, Seismological Press, Beijing, ISBN 7-5028-2215-1. p.105 (2003)

39. Chen, Y.M., Wang, L.M., Dai, W., Wang, W.F., Dai, H.G.: The frozen soils and devastating characteristics of west Kunlun Mountains Pass Ms 8.1 Earthquake Area in 2001, Earthquake Research in China, 20(2), 2004, 161-169

40. Hoek, E., Bieniawski, Z.T.: Brittle rock fracture propagation in rock under compression. Int. J. Fract. Mech. 1(3), 137-155 (1965)

41. Fan, T.Y.: Fundamentals of Fracture Mechanics. Science Press, Beijing, ISBN 7030109945, p.517 (2003) (in Chinese)

42. Xiao, H.T., Yue, Z.Q.: New Boundary Element Analysis of Fracture Mechanics in Functionally Graded Materials. Higher Education Press, Beijing. p.278 (2011). (in Chinese)

43. Yu, H.S.: Cavity Expansion Methods in Geomechanics. Kluwer Academic Publishers, Boston. ISBN 0412799901. p.385 (2000)

44. Yue, Z.Q.: On possible primary precursor of ground methane gas abnormal for early prediction of next damage earthquake, paper in preparation (2013).

45. Mann, P., Gahagan, L., Gordon, M.B.: Tectonic setting of the world's giant oil and gas fields, in M. T. Halbouty, ed., Giant Oil and Gas Fields of the Decade 1990-1999, AAPG Memoir 78, p. 15-105 (2003). 